\title{
LAS COOPERATIVAS DE TRABAJO ASOCIADO: UNA ALTERNATIVA DE TRABAJO DIGNO, SOSTENIBLE E INCLUSIVO
}

\section{Dulce Soriano Cortés}

Profesora Contratada Doctora Derecho del Trabajo y Seguridad Social

Facultad de Derecho

Universidad de Cádiz

https://orcid.org/0000-0002-0827-0174

\section{RESUMEN}

Este trabajo presenta una reflexión sobre el singular estatuto jurídico de las personas socias trabajadoras en las cooperativas de trabajo asociado. La naturaleza societaria que la ley otorga al vínculo contractual, no impide reconocer la inexorable conexión que tales socios trabajadores guardan con el ámbito de las relaciones laborales. El marco competencial constitucional y la diversificada regulación autonómica no favorecen la configuración de un adecuado estatuto jurídico para ellos. Es necesario aprovechar las sinergias de impulso internacional y comunitario en favor de las cooperativas como alternativas que generan trabajo decente y contribuyen al desarrollo sostenible, con empleos estables, seguros e inclusivos. Los poderes públicos han de contribuir a tales objetivos diseñando políticas públicas que favorezcan buenas prácticas laborales en este contexto, ejerciendo vigilancia y control para su efectividad. Finalmente, la libertad sindical en este marco, representa un paso decisivo en el reconocimiento y ejercicio de los derechos laborales.

PALABRAS CLAVE: Cooperativas de trabajo asociado, socio trabajador, trabajo decente, libertad sindical.

CLAVES ECONLIT / ECONLIT DESCRIPTORS: P13, k31, J54, J50.

Cómo citar este artículo/How to cite this article: SORIANO CORTÉS, Dulce: "Las cooperativas de trabajo asociado: una alternativa de trabajo digno, sostenible e inclusivo", CIRIEC-España, Revista Jurídica de Economía Social y Cooperativa, $\mathrm{n}^{\circ} 38,2021$, pp. 11-54. D0I: 10.7203/CIRIEC-JUR.38.20864 


\section{WORKER COOPERATIVES: AN ALTERNATIVE FOR DECENT, SUSTAINABLE AND INCLUSIVE WORK}

\section{EXPANDED ABSTRACT}

This work presents a reflection on the singular legal status of the working partner in worker cooperatives. Among the purposes and mission of the ICA, included in the "Strategic Plan 2020-30", is the need to pay more attention to the dignity of work as one of the pending challenges. Consequently, combating unequal working conditions for the working partners, seeking a legitimate equalization to working conditions and recognized rights for employed workers, constitutes a plausible goal to be achieved within its lines of action for this decade; Failure to do so could be considered an attack against the cooperative principles and values, enshrined by the ICA and included as an annex to IL0 Recommendation 193, from which one of the central pillars of the social and solidarity economy is extracted, which is, the approach of the people-centered economy.

The corporate nature that Spanish law grants to the contractual relationship between the working partners and the cooperative does not prevent us from recognizing the inexorable connection that these working partners have with the field of labor relations. The exclusion of such workers from the workplace is not based on the peculiarities of the service they perform or on their subjection to the company, but responds to a specific option of legislative policy motivated by the presumption that the cooperative pursues objectives based on solidarity, democracy and mutualism. On the other hand, the heterogeneous regional legislative framework that derives from the competence framework of the Spanish Constitution does not favor the configuration of an adequate legal status for the worker members of associated work cooperatives. However, all this should not constitute a justification for not guaranteeing equal and decent working conditions for the working partners. It is inadmissible that the working partners enjoy less favorable working conditions than those that would correspond to them if they were employed. The very competitive pressures of the market in which these cooperatives operate, together with the lack of guarantees regarding their working conditions, constitute a favorable framework for "self-exploitation". Hence, the necessary intervention in the key of guardianship to guarantee minimum standards of labor protection and homogeneous working conditions for these worker partners; and this, regardless of the fact that within the current legislative framework we cannot formally qualify it as an employment relationship stricto sensu.

In order to achieve these objectives, the synergies derived from regulations at the international level must be taken advantage of, within the framework of the IL0, as well as in the 
context of community-level initiatives that enhance the social economy. Specifically, it is necessary to take advantage of the momentum in favor of cooperatives as alternatives that generate decent work and contribute to sustainable development, with stable, safe and inclusive jobs. This framework will serve to carry out a decisive impulse to the consolidation of labor standards for the working partners of the associated work cooperatives. On the one hand, the concept of decent work, configured within the ILO, constitutes the legal bastion to jointly and unitaryly address minimum regulatory standards, applicable to all working people, in particular, to the group that concerns us, the working partners. On the other hand, the supports of the European Union to this sector, as the axis for the social and economic reconstruction of the EU; particularly, the implementation of a legal Statute for the European social enterprise in order to create the "European Label of social economy" should favour the consolidation of "good labor practices" within the framework of associated work cooperatives.

On the other hand, at the national level, the public authorities play a fundamental role in the objectives described, not only by reinforcing the implementation of adequate labor standards through public policies that qualitatively value these social advances, but also by carrying out effective periodic controls that verify their effectiveness and, consequently, imposing appropriate sanctions for non-compliance. Public policies in this sense would lay the foundations for carrying out legislative reforms in this line, following some of the measures already contemplated at the regional level, such as, for example, the equalization of corporate advances to the salaries provided for in the corresponding collective agreement. It would be desirable for such practices to be extended to other working conditions. Similarly, gender equality policies should be favored, promotion of employment for young people or vulnerable groups, or also, measures for reconciling family and professional life that are effectively translated into joint responsibility of both parents, etc. And this, in addition, to other policies in favor of "green employment" and renewable energies, which are respectful with the planet. All of this would contribute to the associated work cooperatives effectively representing an alternative of decent, sustainable and inclusive work, in accordance with the purposes of the ICA.

On the other side, we must emphasize that the recognition of certain minimum labor standards for the working partners, not only would it combat "self-exploitation" of the working partners, but would also help to combat the "false cooperativism". It is known that recourse to cooperativism does not always respond to the objectives and principles that inspire it, but that some business initiatives use it as an alternative to circumvent labor legislation, since the cooperative framework can offer them greater profitability, reduction of salary and social costs, as well as, fewer controls and demands on the power of business management, and likewise, less or no union control. These practices, located within the framework of the illegal 
transfer of workers, are not only contrary to the purposes of social utility and principles that inspire cooperativism, but also contribute to generating unfair competition, which ultimately and ultimately results in negatively on the people who provide service in such entities.

Finally, we must highlight the undoubted progress that has taken place in the field of collective rights of worker members as a result of the recent pronouncements of the Supreme Court on the matter. It is clear to admit that the working partners can legitimately harbor alternative interests that are strictly labor-related that go beyond those of the corporate relationship, for whose defense the channels of participation in the governing bodies of cooperatives derived from their condition of partners may be notoriously insufficient. The differences of interests between the working partners and the cooperative intensify as the size of the cooperative increases, where members are further removed from the governing and management bodies, represented in the Governing Council. The recognition of the right to freedom of association in the context of the working partners of associated work cooperatives, carried out by the Supreme Court, opens possibilities for union action, both individually and collectively. In the absence of the recognition of other channels of representation for the promotion and defense of the interests of the working partners in the framework of the provision of services, the union channel deploys all its resources in the field of these cooperatives, which undoubtedly it has to translate into an engine of change and progress in the recognition and exercise of labor rights. Also in this matter, it is necessary to take advantage of the normative impulses in the supranational sphere. We refer, on the one hand, to the important contribution that the ILO can make in its work of control regarding the compliance and application by the States of the fundamental labor conventions to the working partners of the associated work cooperatives, particularly, in in relation to ILO Convention 87, "Convention relative to freedom of association and protection of the right to organize". And, at the community level, we must highlight Directive 2003/72/EC of the Council, of July 22, 2003, which completes the "Statute of the European cooperative society with regard to the involvement of workers" in which mechanisms for information and consultation of workers and, therefore, for collective participation are established. All of this is paralleled by the collective dimension of labor rights that we are analyzing.

KEYWORDS: Worker cooperatives, working partners, decent work, freedom of union. 


\section{SUMARIO}

I. Naturaleza jurídica de la relación entre el socio trabajador y la cooperativa de trabajo asociado. II. Revisión armonizadora de las fuentes regulatorias. 2.1. Marco nacional. 2.2. Marco supranacional. III. El controvertido estatuto jurídico del socio trabajador. IV. Libertad sindical en el marco de las cooperativas de trabajo asociado. V. Conclusiones. Bibliografía.

\section{Naturaleza jurídica de la relación entre el socio trabajador y la cooperativa de trabajo asociado}

Como es sabido, la cooperativa de trabajo asociado constituye una singular variedad de cooperativa en la que están presentes los rasgos definitorios de toda cooperativa, esto es, estamos ante "una sociedad constituida por personas que se asocian, en régimen de libre adhesión y baja voluntaria, para la realización de actividades empresariales, encaminadas a satisfacer sus necesidades y aspiraciones económicas y sociales, con estructura y funcionamiento democrático, conforme a los principios

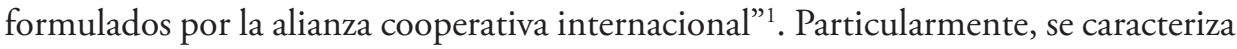
porque "tienen por objeto proporcionar a sus socios puestos de trabajo, mediante su esfuerzo personal y directo, a tiempo parcial o completo, a través de la organización en común de la producción de bienes o servicios para terceros. También podrán contar con socios colaboradores"2. Además, el propio precepto explicita que "la relación de los socios trabajadores con la cooperativa es societaria”. La singularidad de este tipo de cooperativa viene dada por ofrecer trabajo remunerado a sus socios; no obstante, en cuanto a su objeto no se diferencia del resto de sociedades mercantiles, pues, concurren en el mercado ofreciendo bienes y servicios. Dicho de otro modo, el principio mutualista que late en la finalidad de este tipo de cooperativa, no ha de confundirse con su objeto social, que no deja de ser una actividad económica. Por supuesto, en este tipo de cooperativas han de estar presentes los diez valores ${ }^{3}$ y

1. Art. 1 de la Ley 27/1999, de 16 de julio, de Cooperativas, (BOE 17 de julio). En adelante, LC.

2. Art. 80 LC.

3. La autoayuda, autorresponsabilidad, democracia, igualdad, equidad y solidaridad. Y, junto a ello, añadir los valores éticos de honestidad, actitud receptiva, responsabilidad social y respeto hacia los demás. 
siete principios ${ }^{4}$, consagrados por la Alianza Cooperativa Internacional (ACI) ${ }^{5}$ y que constituyen el mínimo común denominador de todas las cooperativas de todos los sectores y de todas las regiones. Dentro del propósito y misión de la ACI, renovado y reforzado en su "Plan Estratégico 2020-30" destacamos, por lo que nos ocupa, su preocupación por la necesidad de prestar más atención a la dignidad del trabajo.

La naturaleza jurídica de la relación entre el socio trabajador y la cooperativa de trabajo asociado, sin duda, constituye el eje nuclear del debate jurídico que tradicionalmente ha venido condicionando la determinación de su estatuto jurídico ${ }^{7}$. No es una cuestión coyuntural ni nueva, pues, arranca desde los años setenta con una intensa polémica doctrinal que básicamente puede reconducirse a tres posiciones: quienes defienden su naturaleza societaria, los que abogan por su naturaleza laboral y los defensores de una naturaleza mixta; debate del que también se hizo eco tempranamente la jurisprudencia ${ }^{8}$. Por nuestra parte, carecería de interés práctico reproducir las argumentaciones ampliamente ya analizadas por la doctrina'; más bien, partiendo de sus aportaciones ponemos de manifiesto que en esta figura del socio trabajador existe una "alta probabilidad" de que concurran las notas de laboralidad ${ }^{10}$, si bien, entendemos que no ha existido voluntad política para su reconocimiento. Especialmente destacables son los intensos esfuerzos de la doctrina laboralista por fundamentar en sede teórica la constatación de tales notas de laboralidad en esta

4. Afiliación voluntaria y abierta; control democrático de los miembros; participación económica de los miembros; autonomía e independencia; educación, formación e información; cooperación entre cooperativas; y, sentimiento de comunidad.

5. Estos principios fueron recogidos textualmente como anexo en la Recomendación OIT sobre promoción de cooperativas (2002), a la que nos referiremos posteriormente.

6. ACI, "Un camino centrado en las personas para una segunda década cooperativa", Plan Estratégico 20202030, (Enero de 2020).

7. Vid. FAJARDO GARCÍA, I.G. (dir.) \& SENENT VIDAL, M.J. (coord.): Cooperativa de trabajo asociado y estatuto jurídico de sus socios trabajadores, Tirant lo Blanch, València, 2016.

8. STS de 19 de mayo de 1987.

9. Damos aquí por reproducida todas aquellas posiciones doctrinales ampliamente expuestas por, entre otros, LÓPEZ GANDÍA, J.: Las cooperativas de trabajo asociado y la aplicación del derecho del trabajo, Tirant lo Blanch, València, 2006, pp. 35 y ss.

10. Vid. MONTOYA MELGAR, A.: "Sobre el socio-trabajador de la cooperativa de trabajo asociado". En: Estudios de Derecho del Trabajo en memoria del profesor Gaspar Bayón Chacón, Editorial Tecnos, Madrid, 1980, pp. 139-154. En este mismo sentido, se ha destacado que existen "un sin fin de circunstancia que denotan, con las matizaciones que se quieran, situaciones de subordinación, dependencia y ajenidad", en GARCÍA JIMÉNEZ, M.: "El desamparo del trabajo asociado por la legislación laboral o el limbo del trabajo cooperativizado", Revista General de Derecho del Trabajo y de la Seguridad Social, no 37, 2014, p. 115. 
(pp. 11-54)

prestación de servicios del socio trabajador para la cooperativa de trabajo asociado; particularmente, las reflexiones en torno a los conceptos de ajenidad ${ }^{11}$, dependencia ${ }^{12}$ y retribución ${ }^{13}$. Recientemente el propio Tribunal Supremo ha reconocido a la relación del socio trabajador con la cooperativa como una "prestación de trabajo subordinada, aunque las notas de dependencia y, especialmente, la de ajenidad, ofrezcan un perfil menos intenso que el de la relación laboral típica o común"14. Lo cierto es que, a nuestro juicio, resulta palmario admitir que los socios trabajadores pueden legítimamente albergar unos intereses alternativos estrictamente laborales que van más allá de los propios de la relación societaria, para cuya defensa pueden resultar notoriamente insuficientes los cauces de participación en los órganos de gobierno de las cooperativas derivados de su condición de socios. Las diferencias de intereses entre

11. Este rasgo de la "ajenidad" ha sido el que más dificultad ha presentado a la hora de su fundamentación. Nos hacemos eco de algunas de esas argumentaciones: ORTIZ LALLANA, M.C.: La prestación laboral de los socios en las cooperativas de trabajo asociado, J.M. Bosch Editor, Barcelona, 1989, pp. 34 y ss.; explica la ajenidad en los frutos entendiendo que la sociedad cooperativa se apropia de forma originaria de los frutos del trabajo del socio trabajador; SANTIAGO REDONDO, K.M.: Socio de cooperativa y relación laboral, IBIDEM Ediciones, Madrid, 1998, pp. 236 y ss.; parte de la "teoría de la emancipación patrimonial" entendiendo que el patrimonio de la cooperativa es independiente del de cada uno de los socios y considera que la "plusvalía del trabajo" del socio-trabajador pertenece de forma originaria a la cooperativa, pues, solo después y en virtud de acuerdo asambleario se acuerda su reparto; hecho este que por otro lado también es posible respecto de los trabajadores por cuenta ajena, propiamente dichos, pues, a ellos también se les puede hacer partícipes de dicho beneficio. PALOMEQUE LÓPEZ, M.C.: "El trabajo autónomo y las propuestas de refundación del Derecho del Trabajo", Relaciones Laborales: Revista crítica de teoría práctica, no 1, 2002, pp. 429 y ss.; toma como referencia el concepto de" ajenidad en el mercado" del Profesor ALARCÓN CARACUEL y al respecto, entiende que los socios trabajadores no ofrecen el fruto de su trabajo directamente al mercado sino a través de la cooperativa.

12. Menos cuestionamiento ha planteado la "dependencia" o "subordinación". Vid. ESPÍN SÁEZ, M.: El socio trabajador. Criterios para sistematizar la realidad del autoempleo colectivo, Consejo Económico y Social (CES), Madrid, 2009, pp. 135 y 136; incide en la innegable existencia de una relación de dependencia entre el socio trabajador y la cooperativa, pues, están sometidos a un régimen disciplinario, directamente relacionado con su prestación de servicios, preestablecido en los Estatutos o Reglamentos de Régimen Interno (art. 82 LC), donde se recoge entre las posibles sanciones, la extinción del contrato y expulsión del socio, medidas disciplinarias que no se corresponden con mecanismos de autodefensa de los socios, sino en tanto que trabajadores.

13. El art. 80.4 LC reconoce que "los socios trabajadores tienen derecho a percibir periódicamente, en plazo no superior a un mes, percepciones a cuenta de los excedentes de la cooperativa denominados anticipos societarios que no tienen la consideración de salario, según su participación en la actividad cooperativizada”. Es innegable el paralelismo significativo de tales "anticipos" con el "salario", ya que se trata de la contraprestación por el trabajo realizado para la cooperativa, y ello, aun cuando el legislador no pueda calificarlos como tal después de haber declarado el carácter societario de la relación. En este sentido, vid. MORGADO PANADERO, P.: "El régimen laboral y de Seguridad Social de los socios trabajadores en las cooperativas de trabajo asociado", Actualidad Laboral (AL), no 28, 2002, pp. 565 y ss.

14. STS 8 de mayo de 2019, (rec. 42/2018). 
el socio trabajador y la cooperativa se intensifican a medida que aumenta el tamaño de la cooperativa, donde los socios están más alejados de los órganos de gobierno y dirección, representados en el Consejo Rector ${ }^{15}$.

Todo ello, evidencia y fundamenta una necesaria intervención en clave de tutela para garantizar unos mínimos estándares de protección laboral y unas homogéneas condiciones de trabajo para estos socios trabajadores; y ello, con independencia de que dentro del actual marco legislativo no podamos calificarla formalmente como relación de trabajo stricto sensu. Compartimos criterio con quienes han afirmado que la exclusión de tales trabajadores del ámbito laboral no se basa en las peculiaridades de la prestación que desempeñan o en la sujeción a la empresa sino que responde a una concreta opción de política legislativa motivada por la presunción de que la cooperativa persigue unos objetivos basados en la solidaridad, la democracia y el mutualismo ${ }^{16}$.

En este sentido, también la jurisprudencia desde hace años ha reconocido la singularidad de esta figura, pues, admitiendo el presupuesto legal que la califica como relación societaria, considera que "ello no puede ocultar y esconder que ínsita en dicha relación existe una realidad que no es posible desconocer y que consiste en la presencia de un trabajo subordinado realizado por el socio trabajador que está sujeto al ámbito de organización y dirección de la Cooperativa que se personifica en su Consejo Rector" ${ }^{17}$. Esta compleja posición lleva al Tribunal Supremo a reconocer que estamos ante un estatus jurídico de carácter mixto, cuya singularidad deriva de la relación societaria sobre la que se asienta y, al mismo tiempo, se manifiesta en la prestación de una actividad de trabajo con tratamiento jurídico laboral en gran medida ${ }^{18}$; de ahí que también reconozca que para solucionar los conflictos producidos en este área de trabajo se deba acudir a la Legislación Laboral, para las cuestiones no previstas específicamente por la legislación ${ }^{19}$.

15. Al Consejo Rector corresponde, "al menos, la alta gestión, la supervisión de los directivos y la representación de la sociedad cooperativa, con sujeción a la Ley, a los Estatutos y a la política general fijada por la Asamblea General" (art. 32 LC).

16. Vid. ESCRIBANO GUTIÉRREZ, J.M.: "Cooperativas de trabajo asociado y derechos laborales colectivos de los socios-cooperativistas", Revista de Derecho Social (RDS), no 49, 2010, p. 102; quien pone de manifiesto que la compatibilidad de la condición de socio y trabajador ya ha sido reconocida por el legislador en figuras próximas, como ocurre en el marco de las sociedades laborales. Actualmente, previsto en los arts. 18 y ss. de la Ley 44/2015, de 14 de octubre, de Sociedades Laborales y Participadas (BOE 15 de octubre).

17. Por todas, STS 8 de mayo de 2019, (rec. 42/2018).

18. Entre otras, SSTS 10 de diciembre de 2013, Rcud. 3256/2012; Rcud. 3201/2012 y STS de 27 de noviembre de 2013, Rcud. 3128/2012.

19. STS de 29 de Mayo del 1990 , ROJ:4099/1990. 
(pp. 11-54)

Manifestación de ese innegable vínculo con el ámbito laboral, es la atribución al orden jurisdiccional de lo social, de la competencia para conocer de los conflictos originados entre las cooperativas de trabajo asociado y sus socios trabajadores, si bien, exclusivamente en lo referido a "la prestación de sus servicios"(art. 2, c) LRJS) ${ }^{20}$.

Del mismo modo, el propio legislador ha venido aplicando esa técnica de extensión de la protección de la legislación laboral al llevar a cabo una asimilación a los "trabajadores por cuenta ajena" en determinadas materias. Sirvan como ejemplo, la "sucesión de contratas y concesiones"21, o las "medidas de fomento para la creación de empleo" 22 . En cambio, en otros aspectos de la prestación de servicios, la regulación aplicable para esta figura del socio trabajador queda por debajo de la protección que la legislación laboral otorga a los trabajadores por cuenta ajena, o bien, carecen de cobertura legal. Esto supone a la postre una desregulación de la prestación de servicio de los socios trabajadores, que los coloca en "una especie de limbo"23 en todos aquellos aspectos a los que la legislación laboral no se ha referido expresamente; condición esta que también ha sido calificada como "trabajador parasubordinado"24. Sin duda, tal singularidad de sus rasgos definitorios la convierte en una de las "zonas grises" del Derecho del Trabajo que evidencia las fronteras siempre móviles del contrato de trabajo y que se ha materializado en necesarias resoluciones judiciales que han ido marcando las lindes entre ambos tipos de relaciones jurídicas: la relación laboral y la relación

20. Art, 2, c) de la Ley 36/2011, de 10 de octubre, reguladora de la jurisdicción social (BOE 11 de octubre). En adelante, LRJS. Por su parte, así lo reitera el art. 87 LC.

21. "Cuando una cooperativa de trabajo asociado cese, por causas no imputables a la misma, en una contrata de servicios o concesión administrativa y un nuevo empresario se hiciese cargo de éstas, los socios trabajadores que vinieran desarrollando su actividad en las mismas tendrán los mismos derechos y deberes que les hubieran correspondido de acuerdo con la normativa vigente, como si hubiesen prestado su trabajo en la cooperativa en la condición de trabajadores por cuenta ajena” (art. 86.2 LC).

22. "Serán de aplicación a los socios trabajadores de las cooperativas de trabajo asociado y a los socios de trabajo de las otras clases de cooperativas todas las normas e incentivos sobre trabajadores por cuenta ajena que tengan por objeto la consolidación y creación de empleos estables, tanto las relativas a la Seguridad Social como a las modalidades de contratación”, (Disposición Adicional Duodécima LC).

23. Vid. GARCÍA JIMÉNEZ, M.: "La discriminación del trabajo cooperativizado", CIRIEC-España, Revista de Economia Pública, Social y Cooperativa, no 52, 2005, pp. 387-409; ibid.: "El desamparo...”, pp. 105-122.

24. Concebido como la persona que, teniendo la condición de trabajador autónomo, se sitúa en una posición próxima a la ostentada por un trabajador por cuenta ajena. En este sentido, vid. MONEREO PÉREZ, J.L. \& TRIGUERO MARTÍNEZ, L.A.: "La configuración técnica de la relación laboral del socio trabajador de cooperativas de trabajo asociado", Revista General de Derecho del Trabajo y de la Seguridad Social, no 37, 2014, p.16. 
societaria ${ }^{25}$. La técnica de aplicarles la legislación laboral "por goteo" a través de llamadas concretas y expresas del legislador para extenderles determinadas materias, se ha visto criticada por algún sector de la doctrina por considerar que se trata de una respuesta insuficiente y desorganizada; más bien, se demanda una intervención más general e integradora, sugiriendo su regulación como relación laboral de carácter especial $^{26}$. Ello pasaría por ingresar esta figura en el campo de tutela laboral e integrar sus singularidades por vía legal, esto es, el cierto forzamiento del concepto de trabajo por cuenta ajena que esta propuesta implicaría, quedaría salvado, ex lege y de forma constitutiva, al calificarlo como relación laboral especial. Como apoyo argumental hemos de evidenciar que en algunas de las actuales relaciones laborales especiales las notas de ajenidad y dependencia están aún más difuminadas de lo que puedan estar en el socio trabajador. Conforme a esta alternativa regulatoria, el distinto tratamiento que se le pudiera otorgar al socio trabajador quedaría justificado por la propia singularidad de esta forma de trabajo, y con ello, quedaría salvaguardado el principio de igualdad, esto es, quedaría justificado un tratamiento diferencial siempre que exista una justificación objetiva y razonable ${ }^{27}$. Ciertamente, esta sería una de las posibles alternativas, no la única, que podría contribuir a evitar situaciones de "autoexplotación" en la que tales socios trabajadores puedan encontrarse con unas condiciones de trabajo por debajo de los niveles de tutela de que disfrutan los trabajadores por cuenta ajena del mismo sector; y, de otro lado y a la vez, se evitaría la competencia desleal que ejercen algunas cooperativas falsas ${ }^{28}$ o espurias que se valen de la mera apariencia formal de cooperativa para incurrir, en muchos casos, en supuestos de cesión ilegal de trabajadores y que operan en el mercado con una posición de ventaja por no estar sujetas a las exigencias legales o convencionales del sector en que concurren. Todo ello, adicionalmente, contribuiría a evitar el desprestigio del movimiento cooperativo.

Siendo innegables las conexiones con la legislación laboral, como ya hemos puesto de manifiesto, consideramos que lo más relevante gira en torno al reconocimiento de una serie de derechos laborales de los socios trabajadores, y ello, debe ir ligado a la

25. Vid. MERCADER UGUINA, J.R.: "Contrato de trabajo y contrato de sociedad: una larga historia de encuentros y desencuentros”, Nueva Revista de Derecho del Trabajo, no 172, 2015, p. 10.

26. Vid. LÓPEZ GANDÍA, J., op. cit., pp. 586 y ss.

27. STC 22/1981, de 26 de noviembre. Así se ha argumentado con carácter general en relación a las relaciones laborales especiales, vid. FERNÁNDEZ LÓPEZ, M.F.: "Relaciones laborales especiales y Estatuto de los Trabajadores", RPS, no 189,1983 , pp. 242 y ss.

28. Al respecto, vid. GARCÍA JIMÉNEZ, M.: "Falsas cooperativas, usos abusivos y derechos de los trabajadores. Análisis jurisprudencial y propuestas de actuación”, CIRIEC-España, Revista Jurídica de Economía Social y Cooperativa, no 33, 2018, pp. 185-222. 
(pp. 11-54)

persona del trabajador, conectándolo a la prestación de trabajo, y no necesariamente con la forma jurídica del vínculo con la cooperativa. En esta línea podemos interpretar la respuesta del Tribunal Supremo ${ }^{29}$, a propósito de la jubilación anticipada de un socio trabajador de una cooperativa de trabajo asociado cuya relación se extinguió en el marco del concurso de la entidad, en la que asimiló, a tales efectos -los de la jubilación anticipada-, a todos los trabajadores de las cooperativas (socios y no socios).

Entendemos que están en juego valores constitucionales, algunos de los cuales encuentran amparo directamente en la Constitución, como son: la no discriminación e igualdad de trato, la seguridad y salud o la protección social (arts. 14, 40.2 y $41 \mathrm{CE}$ ); pero, otros, como por ejemplo el derecho a una retribución suficiente se vinculan al "trabajo por cuenta ajena" (35 CE), por lo que requeriría una intervención directa del legislador ordinario ${ }^{30}$. Es por ello que este y otros aspectos relevantes de la prestación de servicios del socio trabajador, actualmente, se encuentran ante un vacío de tutela laboral. Especialmente en las cooperativas de trabajo asociado de ciertas dimensiones, se evidencia un desequilibrio contractual, que demanda una intervención legislativa en clave de tutela en favor de la parte más vulnerable, pues, resulta inadmisible que los socios trabajadores disfruten de condiciones de trabajo menos favorables de las que les corresponderían si fuesen trabajadores por cuenta ajena. Sin necesidad de alterar ni desdibujar la figura jurídica, entre otros motivos por la complejidad y dificultades derivadas del actual cuadro de fuentes normativas internas, como veremos seguidamente, creemos que una idónea y viable propuesta de solución, pasaría por acudir al plano supranacional, concretamente, al concepto de trabajo decente configurado en el marco de la OIT para abordar de forma conjunta y unitaria unos mínimos estándares de regulación, aplicables a todas las personas trabajadoras, y en particular, al colectivo que nos ocupa, los socios trabajadores.

29. SSTS de 20 de noviembre de 2018, rcud. 3407/2016; de 19 de diciembre de 2018, rcud. 2233/2017 y de 7 de febrero de 2019, rcud. 649/2017).

30. Con carácter general, referido al trabajo autónomo, vid. RODRÍGUEZ-PIÑERO ROYO, M. \& CASAS BAAMONDE, M.E.: "El trabajo autónomo y el Derecho del Trabajo", Relaciones Laborales: Revista crítica de teoría práctica, no 1, 2000, p. 7. No obstante, también hemos de reparar en el Preámbulo de Ley 20/2007, de 11 de julio, del Estatuto del trabajo autónomo (BOE de 12 de julio) en el que se refiere, en sentido amplio, a los arts. 35.1, 40.2 y $41 \mathrm{CE}$, en los siguientes términos: "Estas referencias constitucionales no tienen por qué circunscribirse al trabajo por cuenta ajena, pues la propia Constitución así lo determina cuando se emplea el término «españoles» en el artículo 35 o el de "ciudadanos» en el artículo 41, o cuando encomienda a los poderes públicos la ejecución de determinadas políticas, artículo 40, sin precisar que sus destinatarios deban ser exclusivamente los trabajadores por cuenta ajena”. 


\section{Revisión armonizadora de las fuentes regulatorias}

\subsection{Marco nacional}

Desde la perspectiva de las fuentes regulatorias, creemos oportuno analizar, en primer orden, nuestro marco interno, y ello, tanto a nivel constitucional como su desarrollo legislativo. Ello nos permitirá poner de manifiesto las principales dificultades o lagunas que este plano presenta, y, de ahí que presentemos en segundo orden, las fuentes supranacionales, por considerarlo determinante para llevar a cabo un decidido impulso de esta materia.

Aunque el fenómeno cooperativo cuenta con amplia tradición regulatoria en España ${ }^{31}$, nuestro análisis de fuentes ha de partir del marco constitucional. Con carácter general, puede decirse que en la Constitución Española están presentes los Principios consagrados por la $\mathrm{ACI}^{32}$. Sin lugar a dudas, el art. 129.2 CE constituye el marco de referencia en esta materia, estableciendo el siguiente mandato: "los poderes públicos promoverán eficazmente las diversas formas de participación en la empresa y fomentarán, mediante una legislación adecuada, las sociedades cooperativas. También establecerán los medios que faciliten el acceso de los trabajadores a la propiedad de los medios de producción". Voces autorizadas entre la doctrina ${ }^{33}$, ya

31. La primera Ley de Cooperativas española es de 1931. De ella, hemos de destacar dos aportaciones importantes: La primera consistió en incorporar en su art. 1 una noción de cooperativas que fue acogida en lo esencial por sucesivas normas sobre cooperativas (tanto nacionales como latinoamericanas), definiéndolas como "asociación de personas naturales o jurídicas que, sujetándose en su organización y funcionamiento a las prescripciones del Decreto y tendiendo a eliminar el lucro, tenga por objeto satisfacer alguna necesidad común procurando el mejoramiento social y económico de los asociados mediante la acción conjunta de éstos en una obra colectiva”. La segunda aportación importante consistió en llevar a cabo una clasificación de las cooperativas reconocidas legalmente en cinco categorías (cooperativas de consumo, cooperativas de producción, entre ellas, las de trabajadores (arts. 24 a 27); cooperativas de crédito, ahorro y seguros; cooperativas escolares; y, cooperativas mixtas e indeterminadas). A ella, le sucedieron otras leyes de Cooperación en 1938, en 1942, en 1974, en las que se fueron incorporando matices regulatorios, hasta llegar a la Ley General de Cooperativas de 1987, cuya novedad esencial fue la adaptación a la nueva configuración del sistema político y estructura del actual Estado español, y que constituyó el precedente normativo último a la actual normativa vigente, la Ley 27/1999, de 16 julio, de Cooperativas que supuso una adecuación de la normativa específica tanto a la integración en la Unión Europea y la asunción competencial de la materia por parte de las Comunidades Autónomas. Para un análisis más detallado de la evolución histórica de la regulación de las cooperativas en España, véase: NIEVES NIETO, N. de: Cooperativas de trabajo asociado: aspectos jurídico-laborales, Consejo Económico y Social (CES), Madrid, 2005, pp. 29 y ss.

32. Vid. ARROYO SÁNCHEZ, P.: "La Constitución Española y las Cooperativas de Trabajo Asociado", CIRIEC-España, Revista Jurídica de Economía Pública, Social y Cooperativa, no 47, 2003, pp. 77.

33. Vid. PRADO REYES, F.J. \& VIDA SORIA, J.: "Artículo 129: Principios constitucionales sobre la participación social: aplicación y desarrollo". En: Comentarios a la Constitución Española. Tomo X (dir. ALZAGA VILLAAMIL, O.), EDERSA, Madrid, 1998, pp. 94 y ss. 
(pp. 11-54)

destacaron al comentar este precepto que dicho artículo se ha de enmarcar en el contexto socio-económico de los derechos a la propiedad privada y libertad de empresa, consagrados respectivamente en los artículos 33 y 38 de la Carta Magna; se trata de integrar dicha participación para favorecer la armonía en el proceso productivo pero sin alterar los presupuestos del sistema de economía de mercado. De otro lado, su ubicación sistemática, en el Título VII, relativo a "Economía y Hacienda", denota un menor interés del constituyente en relación con otros derechos de participación como es el derecho de libertad sindical o el de huelga, y, además, un inferior nivel de garantía constitucional respecto de otros derechos, como son los ya referidos. Ciertamente, habría sido más adecuada su ubicación en Capítulo III, del Título I, referido a "Principios rectores de la política social y económica", y ello, no solamente por la similitud de contenidos, sino también por la coincidente instrumentación en cuanto al desarrollo normativo requerido, pues, le resultarían aplicables las garantías del art. 53.3 CE, elevándolos a la categoría de principios informadores de la legislación positiva, la práctica judicial y de la actuación de los poderes públicos. No obstante lo anterior, la doctrina ha buscado justificación a su ubicación entendiendo que ello responde a la voluntad de agrupar los mecanismos posibles de intervención en la economía por parte de los poderes públicos ${ }^{34}$.

Concretamente, el art. 129.2 CE cumple una doble funcionalidad: de un lado, reconoce el valor de las cooperativas en orden a lograr una más activa integración de los ciudadanos en los distintos sectores de la actividad económica del país; y, de otro, impulsa y fomenta el fenómeno cooperativo no solo respecto a la constitución de cooperativas, sino en lo referido a una adecuada planificación de medios e instrumentos de desarrollo. Y esto segundo, ha de conectarse particularmente con el art. 40.1 $\mathrm{CE}^{35}$, en el que se hace una llamada a los poderes públicos a orientar sus políticas hacia el pleno empleo ${ }^{36}$.

34. Vid. NOGUEIRA GUASTAVINO, M.: "Artículo 129: la participación de los interesados en la Seguridad Social y en la empresa”. En: Comentario a la Constitución Española: 40 aniversario 1978-2018: Libro-homenaje a Luis López Guerra (dirs. PÉREZ TREMPS, P., SÁIZ ARNAIZ, A. \& coord. MONTESINOS PADILLA, C.), Vol. 2, Tirant lo Blanch, València, p. 1800.

35. Aunque también pueden mencionarse otros preceptos: art. 40.2 CE (en relación a la formación profesional) y art. $50 \mathrm{CE}$ (en relación con el mantenimiento del Estado de bienestar).

36. Los diversos planes anuales de empleo han tomado en consideración entre sus pilares de actuación el apoyo al fenómeno cooperativo. Así, el Plan Anual de Política de Empleo para 2020, prevé dentro de los Objetivos estructurales (Eje 5) el apoyo a la creación y al empleo en cooperativas, (Resolución de 26 de octubre de 2020, de la Secretaría de Estado de Empleo y Economía Social, por la que se publica el Acuerdo de Consejo de Ministros de 20 de octubre de 2020, por el que se aprueba el Plan Anual de Política de Empleo para 2020, según lo establecido en el artículo 11.2 del texto refundido de la Ley de Empleo, aprobado por el Real Decreto Legislativo 3/2015, de 23 de octubre. BOE 2 de noviembre). 
Además, es importante subrayar que el art. 129.2 CE ha de ponerse en conexión con el mandato constitucional a los poderes públicos de favorecer y garantizar la igualdad real de los ciudadanos (art. 9.2 CE). E, igualmente, dicho precepto conecta directamente con la consagración de España como Estado social y democrático de Derecho del art. $1 \mathrm{CE}$; pues, puede entenderse que el art. 129.2 constituye expresa manifestación del Estado social dado el carácter eminentemente social de las cooperativas, lo que justifica el trato favorable que les otorga ${ }^{37}$. De este mandato constitucional se hace eco el art. $108 \mathrm{LC}$, en el que se reconoce como "tarea de interés general", "la promoción, estímulo y desarrollo de las sociedades cooperativas y de sus estructuras de integración económica y representativa”. Ciertamente, esa conexión con el art. 1.1 CE no solo es predicable respecto de las cooperativas en particular sino de la economía social en general; y supone que los poderes públicos están llamados no solo a regular ese sector sino a alentarlo y fomentarlo de una forma adecuada ${ }^{38}$, esto es, "con respeto tanto a la racionalidad instrumental como a la racionalidad de sus fines" 39 . Respuesta a esa potenciación de la economía social en España es la Ley de Economía Social ${ }^{40}$ y, de forma particular, atendiendo igualmente a la llamada de fomento desde instancias comunitarias ${ }^{41}$, la "Estrategia Española de Economía Social

37. Vid. ROJO TORRECILLA, E. \& CAMAS RODA, F.; "Comentario del artículo 129.2 de la Constitución Española de 1978 y su desarrollo (con especial atención a la participación de la empresa)”. En: El modelo social en la Constitución Española de 1978 (dir. SEMPERE NAVARRO, V.), Ministerio de Trabajo y Asuntos Sociales, Madrid, 2003, p. 1946.

38. Ello significa que no se trata de fomentar cualquier cooperativa, sino solo aquella que sirva realmente a su singular interés. "Por tanto, si la cooperativa de trabajo se presenta como un modelo alternativo a empresa capitalista, al servicio del trabajo (decente), para mejorar con ello las condiciones laborales (y de vida trabajador), no pueden caber situaciones de inferioridad admitidas en tal legislación y sí una tutela del objeto pretendido que fundamenta constitucionalmente su fomento", en: GARCÍA JIMÉNEZ, M.: "El desamparo...”, p. 120.

39. Vid. LÓPEZ CANO, A.: Teoria jurídica de la economía social, Consejo Económico y Social (CES), Madrid, 2002, p. 78.

40. Ley 5/2011, de 29 de marzo, de Economía Social. (BOE 30 de marzo), en cuyo art. 8: "Se reconoce como tarea de interés general, la promoción, estímulo y desarrollo de las entidades de la economía social y de sus organizaciones representativas", añadiendo la enumeración de una serie de objetivos que los poderes públicos, en el ámbito de sus respectivas competencias, habrán de integrar en sus políticas de promoción de la economía social. E, igualmente, la Ley 31/2015, de 9 de septiembre, por la que se modifica y actualiza la normativa en materia de autoempleo y se adoptan medidas de fomento y promoción del trabajo autónomo y de la Economía Social, (BOE de 10 septiembre).

41. Conclusiones del Consejo "La promoción de la economía social como motor clave del desarrollo económico y social en Europa" (diciembre de 2015). 
(pp. 11-54)

2017-2020"42 que pretende impulsar sus valores y aumentar su proyección, ya que la economía social se considera un elemento esencial para la recuperación económica y del crecimiento económico sostenible e inclusivo de nuestro país, contribuyendo a la creación de empleo y la cohesión social ${ }^{43}$. El apoyo público a este tipo de iniciativas de economía social debiera llevar aparejada la exigencia de unos estándares mínimos laborales y, además, controles para luchar contra el "falso cooperativismo"; solo así se cumplirá de forma efectiva el objetivo de ser socialmente útiles. Las políticas activas de empleo deben de ser analizadas desde una perspectiva cualitativa ${ }^{44}$; y, desde ese prisma, la sostenibilidad social debe medirse tomando en consideración a la economía social como alternativa de autoempleo digno que promueva los mejores estándares laborales, teniendo como referencia el trabajo decente. Este impulso de la economía social por parte de los poderes públicos se ha de extender también al ámbito de la contratación pública, con la incorporación de cláusulas sociales, conforme dispone el art. 1.3 de la Ley de Contratos del Sector Público ${ }^{45}$; y en ese mismo sentido, la "Estrategia Española de Economía Social 2017-2020" hace alusión a la necesidad de "fomentar el desarrollo de cláusulas sociales de contratación que permitan que el valor diferencial de la Economía Social sea tenido en cuenta en los procesos de contratación pública por parte de las diferentes administraciones", añadiendo como medida específica la de

42. Resolución de 15 de marzo de 2018, de la Secretaría de Estado de Empleo, por la que se publica el Acuerdo del Consejo de Ministros de 29 de diciembre de 2017, por el que se aprueba la Estrategia Espańola de Economía Social 2017-2020 (BOE 20 de marzo).

43. Actualmente, desde el Ministerio de Trabajo se prepara una Estrategia Española de Economía Social 20212027, adecuada a las nuevas realidades, reconociendo su importancia para impulsar la igualdad, la acción climática y los objetivos de desarrollo sostenible (ODS Agenda 2030).

44. Incidiendo en esta cuestión, vid. CANALDA CRIADO, S.: "El fomento del empleo decente y sostenible en cooperativas y sociedades laborales", REVESCO. Revista de Estudios Cooperativos, no 132, 2019, pp. 91 y ss. DOI: https://doi.org/10.5209/REVE.65485

45. "En toda contratación pública se incorporarán de manera transversal y preceptiva criterios sociales y medioambientales siempre que guarde relación con el objeto del contrato, en la convicción de que su inclusión proporciona una mejor relación calidad-precio en la prestación contractual, así como una mayor y mejor eficiencia en la utilización de los fondos públicos. Igualmente se facilitará el acceso a la contratación pública de las pequeñas y medianas empresas, así como de las empresas de economía social”, Ley 9/2017, de 8 de noviembre, de Contratos del Sector Público, por la que se transponen al ordenamiento jurídico español las Directivas del Parlamento Europeo y del Consejo 2014/23/UE y 2014/24/UE, de 26 de febrero de 2014 (BOE 9 de noviembre). Un comentario crítico, destacando las sombras y la no idoneidad de los contenidos "prototipo" de las cláusulas sociales sugeridas por esta ley, al considerar que adolecen de un sesgo hacia la empresa capitalista y que no toman en consideración las características propias de las cooperativas de trabajo asociado, en: CANALDA CRIADO, S.: "Las cláusulas sociales en la contratación pública: un estudio de su idoneidad para el fomento de la economía social", CIRIEC-España, Revista Jurídica de Economía Social y Cooperativa, no 35,2019 , pp. 19 y ss. 
"revisar la normativa vigente para eliminar las limitaciones o trabas a las entidades de economía social para actuar en determinados sectores de actividad", favoreciendo en lo posible la innovación social ${ }^{46}$.

No obstante lo anterior, y después de más de cuarenta años de andadura constitucional, algunas voces consideran que sigue sin cumplirse verdadera y efectivamente el mandato constitucional de fomento del cooperativismo por parte de los poderes públicos $^{47}$.

De otro lado, y también con referencia al marco constitucional, es ineludible hacer mención al reparto competencial entre Estado y Comunidades Autónomas. Como es sabido, la materia de cooperativas no está integrada entre las competencias atribuidas a las Comunidades Autónomas del art. 148.1 CE, ni está recogida en las competencias exclusivas del Estado del art. 149.1 CE; no obstante, las Comunidades Autónomas han ido asumiendo la competencia exclusiva en materia cooperativa en virtud de lo dispuesto en el art. $149.3 \mathrm{CE}^{48}$. Así, pues, la legislación estatal solo será de aplicación a las sociedades cooperativas que desarrollen su actividad cooperativizada en el territorio de varias Comunidades Autónomas, excepto cuando en una de ellas se desarrolle con carácter principal; o bien, a las sociedades cooperativas que realicen principalmente su actividad cooperativizada en las ciudades de Ceuta y Melilla ${ }^{49}$.

Esta configuración normativa tan heterogénea y dispersa planteó debate jurídico desde un principio, pues, ya desde las primeras legislaciones autonómicas se evidenció esa conflictividad en sede constitucional, planteándose problemas interpretativos en torno al alcance y al ámbito funcional y territorial de tales legislaciones ${ }^{50}$. Además,

46. Medida 13, "Estrategia Española de Economía Social 2017-2020”.

47. Vid. DÍAZ RODRÍGUEZ, J.M.: "El mandato constitucional del fomento cooperativo y su desarrollo legislativo, 40 años después", CIRIEC-España, Revista Jurídica de Economía Social y Cooperativa, no 34, 2019, p. 88 .

48. Actualmente, todas las Comunidades Autónomas cuentan con su legislación específica, a excepción de Canarias, cuyo Proyecto de Ley de Cooperativas se encuentra actualmente en proceso de tramitación. En el apartado referido al estatuto jurídico del socio trabajador nos referiremos a las diversas legislaciones autonómicas.

49. Art. 2 LC.

50. Concretamente, la polémica se planteó en orden a determinar si el Derecho de cooperativas se incluía o no en el Derecho mercantil y, por consiguiente, si este debiera entenderse como competencia exclusiva del Estado, en virtud del art. 149.1.6 CE. El Tribunal Constitucional zanjó la controversia estableciendo que la asunción de la competencia legislativa en materia de cooperativas por parte de un Estatuto de Autonomía, ha de situarse dentro del actual ordenamiento vigente y, por tanto, al margen de tal debate doctrinal sobre si las cooperativas son o no sociedades mercantiles. En ese sentido, el Alto Tribunal señaló que las funciones típicas de las cooperativas se manifiestan en las relaciones internas de las cooperativas con sus socios, por lo que las 
ese heterogéneo mapa normativo de legislaciones autonómicas no ha contribuido a favorecer la propia identidad cooperativa ni a la consolidación de los principios cooperativos. Particularmente, respecto a la materia que nos ocupa, todas las legislaciones autonómicas contemplan las sociedades de trabajo asociado. Todas ellas, y también la Ley estatal, no solo regulan los diversos aspectos relativos al funcionamiento de esta singular variedad de cooperativas, sino que abordan otras cuestiones relativas a las relaciones entre los socios trabajadores y la propia cooperativa. Y es ahí donde surge la principal polémica que nos suscita esta materia, pues, al incidir sobre cuestiones puramente laborales, entendemos que inexorablemente tales legislaciones autonómicas, diversas y dispares, podrían incidir de facto en el ámbito de la legislación laboral, que, como es sabido, es competencia exclusiva del Estado (art. 149.1. 7o CE). Igualmente, hemos de conectarlo con el mandato constitucional del art. 35.2 $\mathrm{CE}$ que dispone que el desarrollo del derecho y deber de trabajar, se ha de llevar a cabo a través de la Ley del Estatuto de los Trabajadores, como marco jurídico común y unitario.

La complejidad y problemática que plantea nuestro actual marco normativo interno, caracterizado por la diversificación normativa de cooperativas, como acabamos de exponer, hace necesario poner la mirada y el acento en las fuentes supranacionales, por cuanto entendemos que tales sinergias podrían contribuir a armonizar y garantizar un adecuado estándar de protección laboral.

\subsection{Marco supranacional}

\subsubsection{Organización Internacional del Trabajo}

Como ya anticipamos, en las cooperativas de trabajo asociado han de estar presentes los valores y principios consagrados por la ACI. Dichos principios fueron recogidos textualmente como anexo en la Recomendación 193 OIT sobre promoción de cooperativas ${ }^{51}$, en la que se recuerda que el logro del "trabajo decente" para los trabajadores, dondequiera que se encuentren, es un objetivo primordial de la Organización Internacional del Trabajo. El "trabajo decente", como es sabido, es "el trabajo

relaciones jurídicas externas con terceros no pueden considerarse como funciones típicas de las mismas, sino que constituyen relaciones instrumentales para la consecución de sus fines, similares a las que realiza cualquier otra persona jurídica. En este sentido, STC 72/1983, de 29 de julio, referida al ámbito concreto del País Vasco.

51. Recomendación OIT sobre la promoción de las cooperativas, 2002 (núm. 193). Además, conectada a ella, también cabría destacar la Recomendación sobre la relación de trabajo, 2006 (núm. 198), así como, la Recomendación sobre la transición de la economía informal a la economía formal, 2015 (núm. 204). 
productivo en condiciones de libertad, equidad, seguridad y dignidad, en el cual los derechos son protegidos y que cuenta con remuneración adecuada y protección social" 52 ; dicho concepto gira en torno a cuatro objetivos estratégicos: los derechos en el trabajo, las oportunidades de empleo, la protección social y el diálogo social ${ }^{53}$.

La Recomendación 193 OIT reconoce a las cooperativas como uno de los pilares del desarrollo económico y social, nacional e internacional y pone de manifiesto el importante papel que han de ejercer los poderes públicos estableciendo una política y un marco jurídico favorables a las cooperativas y compatibles con su naturaleza y función. Dentro de las diversas funciones que la Recomendación 193 OIT atribuye a los gobiernos, consideramos de especial interés poner aquí de manifiesto las siguientes: "Promover la aplicación de las normas fundamentales del trabajo de la OIT y de la Declaración de la OIT relativa a los principios y derechos fundamentales en el trabajo, a todos los trabajadores de las cooperativas sin distinción alguna"; "velar por que no se puedan crear o utilizar cooperativas para evadir la legislación del trabajo ni ello sirva para establecer relaciones de trabajo encubiertas, y luchar contra las seudo-cooperativas, que violan los derechos de los trabajadores, velando por que la legislación del trabajo se aplique en todas las empresas"; "promover la igualdad de género en las cooperativas y en sus actividades"; "promover la adopción de medidas para garantizar que se apliquen las mejores prácticas laborales en las cooperativas, incluido el acceso a la información pertinente"; "promover la adopción de medidas relativas a la seguridad y salud en el lugar de trabajo"; "proporcionar formación y otras formas de asistencia para mejorar el nivel de productividad y de competitividad de las cooperativas y la calidad de los bienes y servicios que producen". En definitiva, se insta a los gobiernos a promover el papel de las cooperativas en orden a transformar formas de trabajo de la llamada "economía informal" en trabajo amparado por la legislación. Ha de aprovecharse el histórico y consolidado nexo de colaboración en favor del cooperativismo, entre la ACI y la OIT ${ }^{54}$. Ese apoyo internacional constituye un refuerzo para instar a una regulación a nivel nacional que reconozca e incentive a las

52. Memoria del Director General a la $87^{a}$ reunión de la Conferencia Internacional OIT, Ginebra, junio de 1999.

53. "Trabajo decente es un concepto que busca expresar lo que debería ser, en el mundo globalizado, un buen trabajo o un empleo digno. El trabajo que dignifica y permite el desarrollo de las propias capacidades no es cualquier trabajo; no es decente el trabajo que se realiza sin respeto a los principios y derechos laborales fundamentales, ni el que no permite un ingreso justo y proporcional al esfuerzo realizado, sin discriminación de género o de cualquier otro tipo, ni el que se lleva a cabo sin protección social, ni aquel que excluye el diálogo social y el tripartismo". En, https://www.ilo.org/americas/sala-de-prensa/WCMS_LIM_653_SP/lang--es/ index.htm

54. Este vínculo que se ha visto renovado en el Memorando firmado en 2019. 
cooperativas como formas de empresa que generan trabajo decente y factor clave para afrontar los desafíos del futuro del trabajo. Se trata de reconocerlas como alternativa en la búsqueda del desarrollo sostenible, con empleos estables, seguros e inclusivos ${ }^{55}$.

Consecuentemente, la prestación de servicios en el seno de las cooperativas también debe estar sujeta a los derechos humanos y al trabajo digno como normas universales $^{56}$; lo que nos reconduce ineludiblemente al concepto de trabajo decente de la OIT, entendido como aquel trabajo productivo desarrollado en condiciones de libertad, equidad, seguridad y dignidad ${ }^{57}$. De la Recomendación 193 OIT cabe desprender "la aplicación, en régimen de igualdad, de la legislación laboral a todas las cooperativas y el reconocimiento de todos los derechos y garantías laborales, sin discriminación a todos sus socios trabajadores y de trabajo" ${ }^{8}$.

Ello conlleva la necesidad de establecer un adecuado marco tuitivo que garantice la efectividad de los derechos laborales, también respecto de la prestación de servicios de los socios trabajadores en el marco de las cooperativas de trabajo asociado. Es necesaria la introducción de disposiciones uniformes, precisas y coherentes que regulen sus condiciones de trabajo básicas, en materias tales como: seguridad y salud laboral, protección social, jornada de trabajo y otras condiciones inalienables, reconocidas en las normas laborales tanto de carácter nacional como internacional y consagradas por la $\mathrm{ACI}^{59}$. Precisamente, en el contexto de las cooperativas, consideramos que la OIT desempeña un papel crucial para la implementación de unas condiciones laborales dignas en el marco cooperativo, pero no solo estableciendo una base normativa

55. Con motivo de su centenario, la OIT en su en preocupación por el "Futuro del Trabajo" emitió el informe "Trabajar para un futuro más prometedor" (2019). Uno de los tres ejes sobre los que gira el programa de actuación para los Estados, que se centra en las personas, se refiere a la necesidad de incrementar la inversión en trabajo decente y sostenible, y en la adopción de incentivos para promover las inversiones en áreas clave que lo promuevan. Es ahí donde se sitúa el fomento de la economía social, entre cuyos valores está priorizar las personas y el fin social, frente al beneficio económico.

56. Especialmente, hemos de referirnos a los arts. 6 a 9 del "Pacto Internacional de Derechos Económicos, Sociales y Culturales" (1966), Instrumento de Ratificación de Espańa del Pacto Internacional de Derechos Económicos, Sociales y Culturales, hecho en Nueva York el 19 de diciembre de 1966. (BOE de 30 de abril de 1977).

57. Empleo digno y sostenible se caracteriza por respetar los estándares sociales que recoge el programa de Trabajo Decente, incorporados a la acción de la OIT en la Declaración sobre la justicia social para una globalización equitativa de 2008 .

58. Vid. GARCÍA JIMÉNEZ, M.: “La discriminación...”, p. 405.

59. Declaración mundial sobre el cooperativismo de trabajo asociado, Aprobada por la Asamblea General de la ACI en Cartagena, Colombia, el 23 de Septiembre de 2005. 
armonizadora sino también estableciendo mecanismos de control que garanticen su aplicación ${ }^{60}$.

Hemos de reparar en que el instrumento jurídico utilizado por la OIT para impulsar el apoyo a las cooperativas ha sido a través de Recomendación, y no Convenio. Pero ello no debe analizarse meramente desde la óptica referida a su repercusión jurídica, entendiendo que se trata de materias de segundo plano y que no gozan del carácter vinculante que normativamente tienen los Convenios; más bien, la importancia de las Recomendaciones OIT no se deriva del grado de operatividad de la medida, sino fundamentalmente de su carácter histórico. Concretamente, del art. 19 de la Constitución de la OIT extraemos que las Recomendaciones tienen una naturaleza autónoma que evita la necesidad de ratificación por parte de los Estados miembros de un Convenio específico, en cambio, sí obliga a los Estados a informar sobre su actuación en esta materia; y si a ello, añadimos su procedimiento normativo de doble discusión, igual que los Convenios, las sitúa en "un espacio destacado, como materia transversal y clave para el progreso social y económico sostenible" ${ }^{\prime 6}$. Tales Recomendaciones cabe identificarlas como "buenas prácticas" y diseñan estrategias que podríamos equiparar, en cierto sentido a las políticas de coordinación de la Unión Europa, a través del método abierto de coordinación a que se refiere el art. 153.2, a) TFUE62.

Sin duda, las cooperativas pueden encarnar el fomento del empleo decente y sostenible. Una oportunidad histórica será la Conferencia Internacional de Trabajo en 2022, en la que "la economía social y solidaria para un futuro del trabajo centrado

60. Además del sistema "regular" de control que deriva del art. 22 de la Constitución OIT (obligación de los Estados de informar anualmente a través de memorias sobre las medidas adoptadas para ejecutar los convenios ratificados), ha de ponerse en valor la función de la Comisión de Expertos en Aplicación de Convenios y Recomendaciones (CEACR) aprobada en la IX Conferencia, cuya débil base jurídica es la decisión de la Conferencia pero que en la práctica ha adquirido importancia en el sistema normativo de la OIT. Actualmente, la OIT cuenta con instrumentos propios para asegurar e incentivar el efectivo respeto de los convenios ratificados por parte de los Estados miembros, procedimientos de reclamación y de queja, y también, procedimientos de libertad sindical. En estos momentos la OIT está afrontando la revisión o renovación de los sistemas de control de aplicación de sus convenios. Al respecto, vid. RODRÍGUEZPINEERO Y BRAVO-FERRER, M.: "Prólogo". En: Procedimientos especiales de la OIT: Reflexiones y propuestas en el contexto del centenario (dir. USHAKOVA, T.), Ediciones Cinca, Madrid, 2020, pp. 9 y ss.

61. Al respecto, hemos de precisar que el autor no se refiere específicamente a la Recomendación no 193 que comentamos, sino con carácter general referido a las tendencias actuales de la OIT en materia de trabajo decente; no obstante, entendemos extrapolables sus comentarios a la materia que nos ocupa. En: MONEREO PÉREZ, J.L. \& PERÁN QUESADA, S.: "Configuración y sentido político-jurídico y técnico-jurídico del trabajo decente”. En: El trabajo decente (dirs. MONEREO PÉREZ, J.L., GORELLI HERNÁNDEZ, J. \& VAL TENA, A. de), Editorial Comares, Granada, 2018, pp. 6 y 7. 
en las personas" constituye uno de los puntos del orden del día. Será la primera vez que la discusión sobre Economía Social y solidaria ocupe la atención de los Estados miembros y de los interlocutores sociales. Ello no solo indica la creciente atención a modelos económicos alternativos, centrados en las personas y no en el beneficio, sino que, sin duda, constituirá una excelente ocasión para reflexionar sobre la diversidad de modelos empresariales que tienen su base en los valores de la cooperación, el mutualismo y la solidaridad, y que combinan objetivos sociales, económicos y medioambientales. De forma particular, entendemos que permitirá consensuar y establecer estándares de protección que garanticen unas homogéneas y dignas condiciones de trabajo para los socios trabajadores en las cooperativas de trabajo asociado, equiparables a las de trabajo por cuenta ajena; que, además, podrá contribuir a poner especialmente la mirada en el empleo de los jóvenes, las mujeres y colectivos vulnerables; e, igualmente, supondrá la oportunidad de incidir en un empleo de calidad, entendido como empleo estable, a tiempo completo y que atienda a la corresponsabilidad a la hora de diseńar medidas de conciliación de la vida profesional y familiar, entre otras muchas, condiciones dignas de trabajo; y que, además, sea impulso del "empleo verde" y de las energías renovables.

\subsubsection{Unión Europea}

No podemos cerrar la referencia al marco de fuentes normativas supranacionales sin hacer mención al ámbito de la Unión Europea. Como marco general, hemos de evidenciar la integración de la Carta de los Derechos Fundamentales de la Unión Europea (2000) ${ }^{63}$ al acervo comunitario, con el mismo valor jurídico que los Tratados, donde se consagran los derechos sociales básicos. E, igualmente destacable es el capítulo II del "Pilar Europeo de Derechos Sociales" $(2017)^{64}$ en favor de condiciones de trabajo justas.

Específicamente en materia de cooperativas, contamos con dos normas relevantes: de un lado, el Reglamento (CE) n ${ }^{\circ}$ 1435/2003 del Consejo, de 22 de julio de 2003, relativo al Estatuto de la sociedad cooperativa europea; y, de otro, la Directiva 2003/72/CE del Consejo, de 22 de julio de 2003, por la que se completa el Esta-

63. Destacamos en este punto, especialmente, el art. 31 referido a "Condiciones de trabajo justas y equitativas", en el que se reconoce que: "1. Todo trabajador tiene derecho a trabajar en condiciones que respeten su salud, su seguridad y su dignidad. 2 . Todo trabajador tiene derecho a la limitación de la duración máxima del trabajo y a períodos de descanso diarios y semanales, así como a un período de vacaciones anuales retribuidas" (Diario Oficial de las Comunidades Europeas, de 18 de diciembre de 2000, (2000/C 364/01).

64. Adoptado en la Cumbre social celebrada en Gotemburgo (Suecia) en noviembre de 2017. 
tuto de la sociedad cooperativa europea en lo que respecta a la implicación de los trabajadores $^{65}$. Este Reglamento constituyó la primera normativa propia en materia de cooperativas en el ámbito de la Unión Europea integrada en el área del derecho de sociedades ${ }^{66}$. Se trató, por tanto, de un nuevo instrumento normativo europeo regulador del régimen jurídico de las cooperativas de ámbito europeo que permitió ofrecer un marco para la intensificación de las actividades transnacionales a las sociedades cooperativas, utilizando para ello los instrumentos que corresponden a sus características especiales $^{67}$. Ciertamente, se crearon muy pocas sociedades cooperativas europeas $^{68}$, lo que llevó a las instituciones comunitarias a cuestionarse esa escasa eficiencia práctica de la normativa comunitaria y a reflexionar en profundidad sobre sus motivos, analizando las necesidades específicas y obstáculos de carácter nacional en relación con la internacionalización de las cooperativas.

A nivel comunitario, las bases de los elementos definitorios de la economía social se refieren a: a) empresas para las cuales el objetivo social de interés común es la razón de ser de la acción comercial, que se traduce a menudo en un alto nivel de innovación social; b) empresas cuyos beneficios se reinvierten principalmente en la realización de este objetivo social; c) su modo de organización o régimen de propiedad, basados en principios democráticos o participativos u orientados a la justicia social, son reflejo de su misión ${ }^{69}$. Sobre esas bases, podemos constatar en los últimos años, un decidido

65. Ambos publicados en DOUE 18 de agosto de 2003.

66. Un análisis crítico destacando la europeización de la concepción germánica de la cooperativa y sus repercusiones, en: VICENT CHULIÁ, F.: "La sociedad cooperativa europea", CIRIEC-España, Revista Jurídica de Economia Social y Cooperativa, no 14, 2003, pp. 51-82.

67. Por lo que se refiere a la Directiva citada, esta fue transpuesta a nuestro derecho interno mediante la Ley 31/2006, de 18 de octubre, sobre implicación de los trabajadores en las sociedades anónimas y cooperativas europeas; y sustituida por la vigente, Ley 3/2011, de 4 de marzo, por la que se regula la Sociedad Cooperativa Europea con domicilio en España (BOE 8 de marzo).

68. Informe de 2012 de la Comisión al Parlamento Europeo, al Consejo, al Comité Económico y Social Europeo y al Comité de las Regiones. Informe sobre la aplicación del Reglamento (CE) no 1435/2003 del Consejo, de 22 de julio de 2003, relativo al Estatuto de la sociedad cooperativa europea (SCE). COM/2012/072 final.

69. Vid. COMISIÓN EUROPEA: Comunicación de la Comisión al Parlamento Europeo, al Consejo, al Comité Económico y Social Europeo y al Comité de las Regiones: Iniciativa a favor del emprendimiento social. Construir un ecosistema para promover las empresas sociales en el centro de la economía y la innovación sociales, COM (2011) 682 final, Bruselas, 25 octubre, 2011. Tales elementos no tuvieron valor normativo, pero fueron determinantes porque marcaron las bases definitorias de "empresa social" para los posteriores Reglamentos a los efectos de conceder fondos de emprendimiento social. 
impulso comunitario a la economía social ${ }^{70}$. Destacamos el Plan de Acción europeo para potenciar la economía social $(2018)^{71}$ como eje para la reconstrucción social y económica de la UE y particularmente, la puesta en marcha de un Estatuto jurídico para la empresa social europea ${ }^{72}$ con el objeto de crear la "Etiqueta europea de economía social". Se trata de un concepto flexible de empresa social ${ }^{73}$ en la que han de confluir los tres rasgos configuradores básicos, antes mencionados: a) un objetivo social, b) la prioridad en la reinversión de los beneficios, y, c) la gobernanza democrática ${ }^{74}$. Con ella, se trata de impulsar con Fondos de inversión social a aquellas empresas que pongan en marcha "buenas prácticas"75, y, además, se hace hincapié en la necesidad

70. Conclusiones del Consejo «La promoción de la economía social como motor clave del desarrollo económico y social en Europa» (2015) se invita a los Estados Miembros y a la Comisión, en el marco de sus respectivos ámbitos de competencia y dentro del respeto del principio de subsidiariedad, a que establezcan y apliquen estrategias y programas para reforzar la economía social, el emprendimiento social y la innovación social, tanto en el marco del entorno normativo como en el ámbito del acceso a la financiación. Este compromiso ha tenido continuidad y ha culminado en la Declaración de Madrid (2017) "La Economía Social, un modelo empresarial para el futuro de la Unión Europea”, en la que once Estados muestran su apoyo a las diversas formas de la economía social, e igualmente, se aboga por la participación de la Economía Social en el diseño e implantación de la Agenda de los Objetivos de Desarrollo Sostenible 2030.

71. Vid. SOCIAL ECONOMY EUROPE [SEE]: El futuro de las politicas europeas para la Economía Social: Hacia un Plan de Acción, Bruselas, 2018.

72. Resolución del Parlamento Europeo, de 5 de julio de 2018, con recomendaciones destinadas a la Comisión sobre un estatuto para las empresas sociales y solidarias.

73. No se predetermina una forma jurídica concreta, sino que da acogida a las diversas variedades de todos los países de la UE. Además, no han de ser necesariamente, en sentido estricto, entidades sin ánimo de lucro, sino que esa ausencia de lucro conecta con la limitación del reparto de los beneficios, esto es, de forma flexible se admite el reparto de beneficios, pero siempre priorizando la reinversión, para así alcanzar sus fines de carácter social.

74. En contraste, la Ley 5/2011, de 29 de marzo, de Economía Social (BOE 30 marzo), no sigue esa misma sistemática ni contiene una configuración eficiente, si bien, la referencia a entidades (y no empresas) ha de entenderse como equivalente, a los efectos que nos ocupa, y de otro lado, los principios del artículo 4 LES han de ser interpretados ajustándose a los elementos configuradores de la empresa social europea. En este sentido, vid. ALTZELAI ULIONDO, I.: "Un marco jurídico para la empresa social en la Unión Europea", CIRIEC-España, Revista Jurídica de Economía Social y Cooperativa, no 37, 2020, pp. 124 y ss. DOI: https:// doi.org/10.7203/CIRIEC-JUR.37.17845

75. Recomendación 5. (Anexo a la Propuesta de Resolución antes mencionada, sobre un estatuto para las empresas sociales y solidarias): “a) Modelos de gobernanza democrática eficaz; b) procesos de consulta para la definición de una estrategia comercial eficaz; c) adaptación a las necesidades sociales y al mercado laboral, en particular a escala local; d) política salarial, formación profesional, salud y seguridad en el trabajo y empleo de calidad; e) relaciones con los usuarios y los clientes y respuesta a las necesidades sociales no cubiertas por el mercado o el Estado; f) situación de la empresa con respecto a la diversidad, la no discriminación y la igualdad de oportunidades para mujeres y hombres entre sus socios, incluidos los puestos de responsabilidad y de dirección". 
de reforzar los controles periódicos y la importancia de la intervención de los Estados imponiendo sanciones para evitar que sea utilizada indebidamente. Sin duda, esta iniciativa desde el plano comunitario constituirá una oportunidad para garantizar unos estándares de protección para los socios trabajadores de cooperativas de trabajo asociado en el marco de su prestación de servicios. Los fondos de emprendimiento social europeos y la concesión de ayudas podría quedar condicionadas a buenas prácticas en este sentido, vinculadas a la exigencia de tales estándares mínimos laborales para que efectivamente sean socialmente útiles.

\section{El controvertido estatuto jurídico del socio trabajador}

Todas las leyes autonómicas incluyen a las cooperativas de trabajo asociado como una de las categorías posibles dentro de las diversas tipologías que contemplan ${ }^{76}$. Igualmente, cada una de ellas, aunque de diversa forma, regula los rasgos definitorios del estatuto jurídico del socio trabajador; y ello, además de otras cuestiones de interés, como por ejemplo el establecimiento de límites a la contratación de trabajo por cuenta ajena. Excede de los límites marcados en este trabajo, abordar con exhaustividad todas y cada una de esas diferentes regulaciones autonómicas sobre la prestación de servicios de los socios trabajadores; más bien, sin ánimo exhaustivo y a modo ejemplificativo, intentaremos destacar aquellas medidas garantistas y ejem-

76. Las cooperativas de trabajo asociado están reguladas en el siguiente articulado: Arts. 84 a 92 de la Ley 14/2011, de 23 de diciembre, de Sociedades Cooperativas Andaluzas (BOJA 31 de diciembre); Arts. 72 a 74 del Decreto Legislativo 2/2014, de 29 de agosto, del Gobierno de Aragón, por el que se aprueba el texto refundido de la Ley de Cooperativas de Aragón (BOA 9 de septiembre); Arts. 138 a 151 de la Ley 4/2010, de 29 de junio, de Cooperativas del Principado de Asturias, (BOPA 12 de julio); Arts. 102 a 109 de la Ley 1/2003, de 20 de marzo, de cooperativas de las Illes Balears (BOIB 29 de marzo), modificada por Ley 5/2011, de 31 de marzo; Arts. 100 a 107 de la Ley de Cantabria 6/2013, de 6 de noviembre, de Cooperativas de Cantabria (BOC 18 de noviembre); Arts. 130 a 135 de la Ley 12/2015, de 9 de julio, de cooperativas de Cataluńa, (BOE 14 de agosto); Arts. 122 a 127 de la Ley 11/2010, de 4 de noviembre, de Cooperativas de Castilla-La Mancha (DOCM 221, de 16 de noviembre); Arts. 99 a 107 de la Ley 4/2002, de 11 de abril, de Cooperativas de Castilla y León, modificada por Ley 6/2011, de 4 de noviembre, por la que se modifica (BOCL de 10 de noviembre); Arts. 103 a 107 de la Ley 11/2019, de 20 de diciembre, de Cooperativas de Euskadi (BOPV 30 de diciembre); Arts. 146 a 152 de la Ley 9/2018, de 30 de octubre, de sociedades cooperativas de Extremadura (DOE de 2 de noviembre); Arts. 104 a 110 de la Ley 14/2011, de 16 de diciembre, por la que se modifica la Ley 5/1998, de 18 de diciembre, de Cooperativas de Galicia (DOG de 03 de enero); Arts. 103 a 112 de la Ley 4/2001, de 2 de julio, de Cooperativas de La Rioja (BOR de 10 de julio); Art. 105 de la Ley 4/1999, de 30 de marzo, de Cooperativas de la Comunidad de Madrid,(BOCM de 14 de abril); Arts. 104 a 110 de la Ley 8/2006, de 16 de noviembre, de Sociedades Cooperativas de la Región de Murcia (BORM de 7 de diciembre); Art. 67 de la Ley Foral 14/2006, de 11 de diciembre, de Cooperativas de Navarra. (BON 13 de diciembre); Art. 89 del Decreto Legislativo 2/2015, de 15 de mayo, del Consell, por el que aprueba el texto refundido de la Ley de Cooperativas de la Comunitat Valenciana (BOCV de 20 de mayo). 
plarizantes, y de otro lado, las lagunas o críticas más destacadas. Nuestro objetivo es evidenciar que tal heterogeneidad y disparidad normativa no se justifica ni desde una perspectiva jurídico-laboral, ni desde el respeto a los principios cooperativos, pues, uno de los propósitos y misión de la ACI frente a los desafíos globales de esta Década, recogidos en su "Plan Estratégico 2020-2030" es la necesidad de prestar más atención a la dignidad del trabajo. Sin duda, combatir la desigualdad de las condiciones de trabajo de los socios trabajadores en pro de una equiparación respecto a los derechos reconocidos a los trabajadores por cuenta ajena, constituye una loable meta a alcanzar dentro de sus ejes de actuación.

De entrada y con carácter general, es sabido que en materia de Seguridad Social la legislación vigente permite a la cooperativa optar en sus propios estatutos por integrar a los socios trabajadores en el Régimen General de la Seguridad Social, asimilándolos a los trabajadores por cuenta ajena, o bien, integrarlos como trabajadores autónomos en el régimen especial correspondiente ${ }^{77}$. Obviamente, dicha opción ineludiblemente tendrá repercusiones en su estatuto jurídico, como ya se ha puesto de manifiesto por la jurisprudencia ${ }^{78}$.

Los artículos 80 a 87 de la Ley de Cooperativas estatal abordan de forma muy genérica y parcial algunos de los diversos aspectos que afectan a la prestación de trabajo. Por su parte, las diversas legislaciones autonómicas responden básicamente a un patrón muy similar en cuanto a la estructura. De forma generalizada, hacen alusión a las mismas materias, remitiendo la regulación de los aspectos sustanciales del estatuto del socio trabajador a los correspondientes estatutos o reglamentos de régimen interno, si bien, introducen matizaciones al respecto que habrán de ser respetadas por la normativa interna de las cooperativas que operen en los respectivos territorios.

Algunas legislaciones hacen alusiones a los vínculos del socio trabajador con el Derecho laboral, pues, aunque reconocen que la relación entre la persona socia trabajadora y la cooperativa es societaria, añaden que "si bien siempre en consonancia

77. Art. 14 del Real Decreto Legislativo 8/2015, de 30 de octubre, por el que se aprueba el texto refundido de la Ley General de la Seguridad Social (BOE 31 de octubre).

78. Al respecto, véase la STS de 10 de septiembre de 2020 (rec. 1181/2018) en relación al reconocimiento de la prestación contributiva de desempleo a una persona socia trabajadora de cooperativa de trabajo asociado, cuya cooperativa había optado por incluirlos en el Régimen General de la Seguridad Social; y ello, aunque todos los socios estuvieran ligados por parentesco y convivieran en el mismo domicilio. En la sentencia se contrasta con la situación de los socios trabajadores de sociedades laborales. Un comentario a la misma, en: TOMÁS MATAIX, D.: "Prestación por desempleo y socios trabajadores de cooperativas de trabajo asociado. Sobre la posible concesión de la prestación por desempleo a personas socias trabajadoras convivientes y unidos por relación de parentesco. Comentario a la sentencia 752/2020, de 10 de septiembre, de la Sala de lo Social del Tribunal Supremo", CIRIEC-España, Revista Jurídica de Economía Social y Cooperativa, no 37, 2020, pp. 327-338. DOI: https://doi.org/10.7203/CIRIEC-JUR.37.19142 
con la normativa estatal de aplicación"79. En alguna de ellas, se alude a que las condiciones de trabajo sean "condiciones laborales dignas" y que respeten los "estándares laborales mínimos establecidos por la OIT" "80; mención que merece ser subrayada aun cuando lo sea con un carácter genérico. Otras, llevan a cabo una amplia y genérica remisión a la legislación laboral en lo relativo a derechos y obligaciones de socio como persona trabajadora sin perjuicio de las especialidades que se establezcan reglamentariamente ${ }^{81}$; o en parecidos términos, una llamada a la aplicación supletoria o subsidiaria de la legislación laboral en lo no dispuesto específicamente en los estatutos $^{82}$; o explicitando su aplicación en última instancia pero blindando algunas materias particularmente como de orden público ${ }^{83}$. A pesar de que esas remisiones a la legislación laboral han de ser valoradas positivamente, no obstante, hemos de evidenciar que en la práctica algunas de ellas podrían resultar ineficientes ya que buena parte de las garantías que reconoce la legislación laboral van unidas a la intervención de la representación legal de los trabajadores, institución de la que carecen las personas socias trabajadoras. Ejemplo de ello serían decisiones de carácter colectivo en cuanto a traslados o modificaciones sustanciales de las condiciones de trabajo, en las que las garantías de los arts. 40 y $41 \mathrm{ET}$, respectivamente, resultarían inviables en este contexto.

Básicamente, estas son las materias reguladas en la generalidad de las leyes autonómicas en relación a la prestación de servicios de las personas socias trabajadoras:

a) Establecimiento de un periodo de prueba al que puede someterse a los nuevos socios, cuya duración varía según las diversas legislaciones, siendo el más común,

79. Art 104 de la Ley de Cooperativas de Galicia.

80. Art. 105.3 de la Ley de Cooperativas de Euskadi.

81. Art. 87 de la Ley de Cooperativas de Andalucía.

82. Art. 149.2 de la Ley de Cooperativa de Asturias: "En ausencia de regulación cooperativa, se aplicará, supletoriamente, lo establecido en la normativa laboral común”. En igual sentido, la Ley de Cooperativas de Baleares o la de Galicia. En parecidos términos, art. 124.1 de la Ley de Cooperativas de Madrid: “...subsidiariamente, los derechos y garantías legalmente establecidos en el derecho laboral común, sin perjuicio de los derechos reconocidos en la legislación laboral que por afectar al principio de igualdad son de aplicación directa”. Y en idénticos términos a esta última, se recoge en el art. 149.1 de la Ley de Cooperativas de Extremadura.

83. Art. 132 de la Ley de Cooperativas de Cataluña. "A falta de regulación cooperativa, ha de aplicarse lo que disponen las fuentes de derecho cooperativo catalán y, supletoriamente, el ordenamiento jurídico cooperativo en general, y, en último término, la normativa laboral", si bien enumera una serie de materias de orden público vetadas a la autoregulación: a) Las relativas a trabajos nocturnos, insalubres, penosos, nocivos o peligrosos; b) Las normas reguladoras del régimen de seguridad social; c) Las normas sobre prevención de riesgos laborales; d) Las causas legales de suspensión y excedencia. 
(pp. 11-54)

el de seis meses ${ }^{84}$. Algunas legislaciones autonómicas añaden la figura del "socio de trabajo temporal”, figura esta que casa mal con el espíritu mutualista de las cooperativas $^{85}$; además, se establecen límites de porcentajes a cubrir con este tipo de vínculo temporal respecto del total de socios, que oscilan en las diversas legislaciones autonómicas, pero que llegan a alcanzar límites ciertamente elevados ${ }^{86}$. Y, ello, además, de la incorporación de algunas figuras especiales, como son los socios extraordinarios (colaboradores), que únicamente aportan capital al objetivo cooperativizado. Todo esto, resulta contrario a los principios cooperativos $y$, particularmente, choca frontalmente con la supuesta apuesta de la economía social en favor del "empleo de calidad" 87.

b) Reconocimiento del derecho de los socios trabajadores a percibir periódicamente, en plazo no superior a un mes, "anticipos laborales" 88 cuya cuantía por regla general no queda garantizada, salvo en algunas legislaciones autonómicas en las que se exige que no sea inferior al salario mínimo interprofesional en cómputo anual ${ }^{89}$. Ello pone de manifiesto el paralelismo que esta figura guarda con la institución salarial; como igualmente ocurre con algunas otras legislaciones que son verdaderas medidas ejemplarizantes ya que establecen que tales anticipos habrán de equipararse en cuantía similar a las retribuciones de la zona y sector de actividad, según su categoría profesional, sin que en ningún caso sea, igualmente, inferior al salario mínimo interprofesional en cómputo anual ${ }^{90}$. Algunas otras, en términos

84. Algunos ejemplos de periodo de prueba de seis meses: Navarra, Extremadura, Galicia, Cantabria, CastillaLa Mancha, Castilla-León, o Baleares. Algunos otros, lo extienden a nueve meses, como es el caso de La Rioja; o, incluso, hasta un ańo, en el supuesto de Cataluña.

85. Art. 91 de la Ley de Cooperativas de Andalucía, si bien, la actual ley ha reducido a seis años el periodo máximo para ser "socios temporales", frente a la ley previa que lo fijaba en diez años; o, también, el art. 141 de la Ley de cooperativa de Asturias que prevé socios temporales con el límite de tres años.

86. El art. 104.8 Ley de Cooperativas Murcia admite hasta un 30\%. O, en el caso de la Ley de Cooperativas Andaluzas, se señala en un tercio respecto del total de socios (art. 91.2).

87. Vid. ESCRIBANO GUTIÉRREZ, J.: "Empleo de calidad y cooperativas de trabajo asociado: trabajadores por cuenta ajena y socios trabajadores", CIRIEC-España, Revista Jurídica de Economía Social y Cooperativa, $\mathrm{n}^{\circ}$ 24, 2013, pp. 19 y ss.

88. Para un estudio específico, véase: RODRÍGUEZ SANTOS, E.: "El régimen retributivo de las personas socias en las sociedades cooperativas de trabajo: una revisión crítica de los modelos normativos", Temas laborales: Revista andaluza de trabajo y bienestar social, no 144, 2018, pp. 53-87.

89. En este sentido, art. 103.6 de la Ley de Cooperativas de Euskadi; art. 146 de la Ley de Cooperativas de Extremadura; art. 72.7 de la Ley de Cooperativas de Aragón; o, art. 104 de la Ley de Cooperativas de La Rioja.

90. Art. 105.1 de la Ley de Cooperativas de Galicia. 
no muy claros en cuanto al alcance de dicha previsión, reconocen que los anticipos laborales "gozarán de idénticas garantías de protección que las percepciones salariales" ${ }^{\prime \prime}$; esa remisión, entendida en sentido amplio, podría llevarnos a extender a los socios trabajadores la aplicación del art. 28 ET en materia de igualdad retributiva, aplicando respecto a ellos las obligaciones que del mismo se derivan, esto es, las referidas al registro con los valores medios de los salarios que establece su apartado segundo. Este tipo de medidas se integrarían en línea y coherencia con uno de los objetivos marcados por la ACI en el "Plan Estratégico 2020-2030" dirigido a promover la igualdad de género.

c) Regulación de diversas cuestiones relativas a tiempo de trabajo, como son, la regulación de la jornada de trabajo, los descansos semanales, festivos y vacaciones, además de los permisos. Muchas de ellas no introducen precisiones al respecto, remitiendo a los estatutos su regulación; otras, en cambio, reiteran algunas particularidades que a su vez se hacen eco, parcialmente y de forma sesgada, de las previsiones del Estatuto de los Trabajadores. Al respecto, sería deseable que en el marco de su prestación de servicio se pudiese extender a los socios trabajadores la aplicación de la medida dispuesta en el art. 34.9 ET en cuanto a la obligación de llevar a cabo un registro diario de la jornada de trabajo, como medida de control y seguimiento. Esa medida contribuiría a evitar excesos en esta materia.

d) Referencia a las causas de suspensiones. Sustancialmente coinciden con las causas enumeradas en el art. 45 y siguientes del Estatuto de los Trabajadores, si bien, constatamos la falta de actualización de algunas de las regulaciones ${ }^{92}$. De forma particular, se abordan las excedencias, en concreto, la voluntaria, con diversos condicionantes y efectos para su ejercicio. Especial atención dedican todas ellas a los supuestos de causas suspensivas por motivos económicos, técnicos, organizativos y de producción, así como, por fuerza mayor.

e) Referencia generalizada y explícita a la asunción de la legislación en materia de seguridad y salud en el trabajo ${ }^{93}$.

f) Regulación de la materia referida a las contratas. Las legislaciones que la abordan incluyen básicamente dos garantías al respecto: 1) En supuestos de sucesión de

91. Art. 67.4 Ley de Cooperativas de Navarra.

92. Por ejemplo, el art. 73 de la Ley de Cooperativas de Aragón al referirse a la "maternidad y adopción" se remite a la legislación vigente. Ello, debiera leerse con criterio integrador de la actual regulación de esta causa suspensiva en favor de ambos progenitores.

93. Por referir algunos ejemplos, las leyes de Cooperativas de Andalucía, Extremadura, Baleares, Cantabria, Aragón, Galicia; o la de Asturias que expresamente recoge su "inderogabilidad"; o, el supuesto de la Ley de Cooperativas de Cataluńa que la califica, junto a otras, como materia de "orden público", como ya comentamos anteriormente. 
(pp. 11-54)

contratas se establece la continuidad de los socios trabajadores en el caso de cese de actividades, extendiéndoles los mismos derechos y deberes que les habrían correspondido si fuesen trabajadores por cuenta ajena ${ }^{94}$; 2) En determinadas cooperativas que superen un umbral de socios y que cuenten con un cliente principal para el que realicen la mayoría de su actividad, habrá que equipararles las condiciones de trabajo a las que reconozcan los convenios colectivos laborales aplicables a los trabajadores por cuenta ajena del sector o centro de trabajo de la empresa principal para la que presten servicios; y en cuanto a la protección social, debe ser equivalente a la de los trabajadores incluidos en el régimen general de la seguridad social ${ }^{95}$. La doctrina que ha analizado esta segunda medida garantista, la califica como "cooperativa autónoma económicamente dependiente"96 o "cooperativa económicamente dependiente" ${ }^{97}$ por analogía con el "trabajador autónomo económicamente dependiente”, es decir, cuando el 75 \% o más de su facturación anual dependa sólo de un cliente.

g) Regulación del régimen de los ceses o bajas de socios trabajadores por motivos económicos, técnicos, organizativos o de producción, o también por fuerza mayor. La decisión corresponde en la mayoría de las ocasiones a la Asamblea ${ }^{98}$, o alguna previsión específica para cooperativas de gran tamaño en las que en tal caso se atribuye específicamente al Consejo Rector tal decisión ${ }^{99}$. Algunas legislaciones hacen una remisión a la legislación estatal al respecto, entiéndase al despido colectivo ${ }^{100}$, si bien, tal previsión habría de adecuarse a la actual redacción del art.

94. Art. 135 Ley de Cooperativas de Cataluña. Y, en términos similares, las legislaciones cooperativas de Castilla-León, Castilla-La Mancha, Extremadura, Galicia, Cantabria o Baleares.

95. Art. 132.8 de la Ley de Cooperativas de Cataluña, para cooperativas con más de veinticinco trabajadores. En términos similares, el 149.3 de la Ley de Cooperativas de Extremadura, para cooperativas con más de veinte socios.

96. Vid. ROJO TORRECILLA, E.: "Notas a la ley de presupuestos, y a la de acompañamiento, de Cataluña para 2017. La oferta pública de empleo, y una importante modificación de la Ley catalana de cooperativas. ¿Laboralización del cooperativismo de trabajo asociado?”, El Blog de Eduardo Rojo, 2 abril, 2017. Recuperado de http://www.eduardorojotorrecilla.es/2017/04/notas-la-ley-de-presupuestos-y-la-de.html

97. Vid. GARCÍA JIMÉNEZ, M.: “Falsas...”, pp. 208 y ss.

98. Entre ellas, cabe referir, por ejemplo, la Ley de Extremadura, Andalucía o Aragón. O también, se dispone que corresponderá a ésta y en su defecto al Consejo Rector, en el supuesto de Cantabria.

99. Es el supuesto de la Ley de Cooperativas de Valencia, para cooperativas con más de quinientos socios.

100. Art. 126.2 de la Ley de Cooperativas de Castilla-La Mancha: "Las expresadas causas serán debidamente constatadas por la Autoridad Laboral, con arreglo a lo dispuesto en el procedimiento establecido en la legislación estatal aplicable". Esta Ley es previa a la Reforma de 2012 que, entre otros aspectos, como es sabido, suprimió la autorización administrativa a la hora de tramitar los despidos colectivos. 
51 ET en el que el procedimiento gira en torno al obligado periodo de consultas con los representantes de los trabajadores; por lo que en este caso, nuevamente, tal remisión a la legislación laboral encuentra las consiguientes dificultades de operatividad por la ausencia de representantes legales del colectivo que nos ocupa, los socios trabajadores.

h) Regulación del régimen disciplinario, remitiéndose a lo que prevean los estatutos, si bien, reconociendo tal potestad al Consejo Rector ${ }^{101}$. Concretamente, en materia de despidos disciplinarios encontramos alguna remisión en bloque a las causas previstas en la legislación laboral ${ }^{102}$.

i) Finalmente, la regulación de las cuestiones contenciosas. Al respecto, todas las legislaciones autonómicas reiteran la atribución legal al orden social para la resolución de las cuestiones litigiosas que tengan por objeto cuestiones derivadas de la prestación de servicios de los socios trabajadores.

Como hemos podido evidenciar con la anterior muestra ejemplificativa, el hecho de que cada Comunidad Autónoma aplique su particular estatuto de la prestación de servicio genera dispersión normativa, inseguridad jurídica y trato desigual frente a quienes prestan servicio bajo el paraguas del Derecho laboral. Hemos de insistir en que ni el carácter societario de la relación ni el difuso marco de regulación autonómico, debieran constituir impedimento a que de forma efectiva y material se respetasen unas condiciones de trabajo dignas para todos los socios trabajadores. Una vez más subrayamos la necesidad de que los derechos básicos de contenido laboral se deben reconocer en favor de "toda persona", como reconoce el "Pacto Internacional de Derechos Económicos Sociales y Culturales" de $1966^{103}$. Con ello, además, se evitaría que la cooperativa de trabajo asociado sirva para encubrir trabajo precario bajo la

101. El art. 89.9 de la Ley de Cooperativas de Valencia, contempla una singular potestad atribuida al Consejo Rector, la de readmitir o no al socio expulsado, ante resolución judicial que declare la nulidad del acuerdo de expulsión: "Cuando por resolución judicial o arbitral se declare, por contrariar una norma cooperativa, la nulidad del acuerdo de expulsión adoptado por cuestiones relacionadas con la prestación de trabajo o sus efectos, el consejo rector podrá optar entre readmitir a la persona socia o indemnizarla. No obstante, si la resolución declara de forma expresa e indubitada que el acuerdo de expulsión ha vulnerado un derecho fundamental de la persona socia, el derecho de opción corresponderá a esta”.

102. Art. 86.1 de la Ley de Cooperativas de Andalucía.

103. Instrumento de Ratificación de España del Pacto Internacional de Derechos Económicos, Sociales y Culturales, hecho en Nueva York el 19 de diciembre de 1966. (BOE 30-4-1977). En este sentido, vid. GARCÍA JIMÉNEZ, M.: "Falsas...", pp. 211 y ss. 
fórmula societaria, como de hecho ha ocurrido en la práctica en algunos sectores ${ }^{104}$, lo que ha llevado incluso a incorporar en el convenio colectivo estatal del sector, medidas desincentivadoras y vigilantes frente al recurso de este tipo de cooperativas $^{105}$. Ello, como ya hemos reiterado, contraviene los principios inspiradores del cooperativismo, así como, los parámetros de trabajo decente que propugna la OIT y las líneas que configuran la "empresa social europea" a los que nos hemos referido en el apartado anterior.

\section{Libertad sindical en el marco de las cooperativas de trabajo asociado}

Dedicamos este último apartado al análisis del ejercicio de uno de los derechos colectivos en el marco de las cooperativas de trabajo asociado en favor de las personas socias trabajadoras, particularmente, la libertad sindical, pues, sin duda, esta constituye motor de cambio y progreso en el reconocimiento y ejercicio de los derechos laborales. En relación con el trabajo decente, voces autorizadas de la doctrina han señalado con acierto que "uno de los rasgos que favorecen el mayor nivel de cumplimento y eficacia de las normas sociolaborales es el grado de participación de los agentes sociales y el ejercicio del derecho de la libertad sindical. El equilibrio entre normas laborales apropiadas a los contextos sociales y económicos y la fortaleza institucional, determinan el éxito, cumplimiento o fracaso de las regulaciones fiscales, laborales y de protección social en los distintos marcos nacionales. La existencia o ausencia de un sindicalismo libre y plural se nos muestra como un excelente indicador para prever la eficacia y productividad de las economías nacionales y su capacidad de vertebrar sociedades avanzadas y prósperas" ${ }^{106}$.

La laguna regulatoria en lo que hace a los derechos colectivos de los socios trabajadores ya fue evidenciada de forma oportuna hace años por la doctrina laboralis-

104. Concretamente, así se ha evidenciado en el sector cárnico. Comentario y análisis jurisprudencial al respecto en ibid., pp. 191 y ss.

105. “...las partes se comprometen a que en el seno de la Comisión Paritaria ayudarán a remover los obstáculos para la no utilización general de estas cooperativas de trabajo asociado, analizando los motivos de su uso y encontrando fórmulas dentro del contenido del convenio para la reducción de su uso", Disposición Adicional primera del Convenio colectivo estatal de industrias cárnicas. Resolución de 19 de marzo de 2019, de la Dirección General de Trabajo, por la que se registra y publica el Convenio colectivo estatal de industrias cárnicas el (BOE de 19 de abril).

106. Vid. MONEREO PÉREZ, J.L. \& PERÁN QUESADA, S., op. cit., p. 8. 
$\mathrm{ta}^{107}$, poniendo de manifiesto que la latente contraposición de intereses se hace aún más evidente en cooperativas de gran tamaño ${ }^{108}$. Efectivamente, en muchas de esas cooperativas grandes, el carácter asambleario y la condición de copropietario no pasa de ser una mera formalidad que no responde a la realidad ni a parámetros de efectividad $^{109}$, pues, la gestión corresponde a directivos quienes distan mucho de encarnar los intereses de los socios trabajadores, de forma muy similar a la de cualquier otra sociedad. Sin duda, podría afirmarse que la participación de los socios trabajadores en los órganos de decisión y administración de la cooperativa suele ser inversamente proporcional al tamaño de la cooperativa, y en el mismo sentido y proporción, cabe entender la pérdida de protagonismo de la Asamblea de socios frente al Consejo Rector $^{110}$. Además, las propias leyes autonómicas de cooperativas, con la intención de hacer más dinámicas las decisiones asamblearias, de forma diversa, han establecido instrumentos para facilitar dicha gestión interna ${ }^{111}$, que no solo han contribuido a que el socio pierda información de la situación real de la cooperativa, sino que tales mecanismos intermedios también han conducido a una pérdida de protagonismo y visibilidad de los socios en favor del Consejo Rector.

Como es sabido, los socios trabajadores están excluidos de la participación como electores y elegibles respecto de los órganos de representación unitaria en el marco de las cooperativas de trabajo asociado por expreso mandato del legislador ${ }^{112}$. No obstante, algunas legislaciones autonómicas, como la de Navarra o la de País Vasco, contemplan cauces de participación a través de órganos creados al efecto, como es la figura del "Consejo Social" que se instituye como un órgano de participación de los socios cooperativistas, más bien, entendido como órgano de información, ase-

107. Entre otros, vid. ESCRIBANO GUTIÉRREZ, J.: “Cooperativas...”, pp. 97-124.

108. Con especial referencia al supuesto de las Cooperativas de Mondragón. El autor indica que en las cooperativas grandes la participación en el capital social pueda ser tan imperceptible como la existente en cualquier otra empresa donde los trabajadores cuenten con un paquete accionarial. En ibid., p. 99.

109. Vid. LÓPEZ GANDÍA, J., op. cit., p. 550.

110. Sirva como ejemplo, la previsión contenida en el art. 89.3 de la Ley de Cooperativas de Valencia: “... cuando la cooperativa tenga más de quinientas personas socias, el órgano competente para acordar la extinción por causas económicas, técnicas, organizativas o de producción, será el consejo rector”.

111. Tales como: la creación de "secciones cooperativas" o la regulación del "voto delegado".

112. Disposición Adicional primera del RD 1844/1994, de 9 de septiembre, por el que se aprueba el Reglamento de elecciones a órganos de representación de los trabajadores en la empresa (BOE 13 de septiembre). 
(pp. 11-54)

soramiento y consulta de la administración de la cooperativa en lo referente a la prestación de trabajo ${ }^{113}$.

A salvo de esas pioneras y ejemplarizantes iniciativas de participación de los socios trabajadores, la carencia institucionalizada de órganos representativos específicos para reconducir la defensa de los intereses laborales de los socios trabajadores, evidencia la necesidad de canalizarla dicha defensa colectiva de sus intereses a través de la vía sindical de representación. En este contexto de las personas socias trabajadoras se materializa de forma palmaria el papel conferido por la Constitución Española a los sindicatos, arts. 7 y $28 \mathrm{CE}$, en cuanto que encarnan la promoción y defensa de los intereses económicos y sociales que les son propios.

A este respecto, adquiere especial significación el reciente pronunciamiento del Tribunal Supremo en el que se reconoce el Derecho de Libertad Sindical de los socios trabajadores de cooperativas de trabajo asociado y el derecho de los sindicatos a ejercer actividad sindical en ese particular marco de trabajo ${ }^{114}$. El interés de esta sentencia es doble, pues, de un lado, estamos ante el primer pronunciamiento del Tribunal Supremo en esta materia, lo que constituye una singular aportación en la medida en que no existe referencia expresa en la legislación vigente acerca de los socios trabajadores en lo que hace al ámbito subjetivo de la libertad sindical; y de otro, en cuanto al fondo, el reconocimiento de este derecho de libertad sindical en favor de los socios trabajadores supondrá un indudable avance en el reconocimiento y efectividad de derechos en el marco de su prestación de servicios. No hemos de

113. Con una regulación muy detallada de este órgano, art. 57 de la Ley 11/2019, de 20 de diciembre, de Cooperativas de Euskadi. También, en el art. 67.6 de la Ley de Cooperativa de Navarra, se prevé este órgano para "...cooperativas que cuenten con más de cincuenta socios trabajadores...”.

114. STS 8 de mayo de 2019, (rec.42/2018). Se trata de un recurso de casación interpuesto por la organización sindical "Confederación Nacional del Trabajo" (CNT) frente a la sentencia desestimatoria dictada por la Sala de lo Social de la Audiencia Nacional en proceso de tutela de derechos fundamentales en la que la Audiencia Nacional deniega el derecho a la libertad sindical de los socios trabajadores, por considerar que ello no está reconocido en nuestro ordenamiento jurídico, pues, el vínculo con la cooperativa es una relación societaria, y porque los socios trabajadores no son reconducibles a la figura de trabajadores autónomos, en sentido estricto, a que se refiere el art. 3.1 LOLS, por lo que la actuación del sindicato en defensa de los intereses de tales socios trabajadores resulta ilegítima, por carecer de soporte legal. Cuestión distinta, a juicio de la Audiencia Nacional (y con referencia a la STS de 5 de julio de 2017 (23/2016)), serían las cooperativas fundadas en fraude de ley para encubrir relaciones laborales propiamente dichas, en cuyo caso, sí estaría justificada la intervención del sindicato, a quien correspondería la carga de la prueba del fraude de ley. Comentarios a esta sentencia en: GARCÍA MURCIA, J., \& ÁNGEL QUIROGA, M.: "La libertad sindical en las sociedades cooperativas de trabajo asociado. STS-SOC núm. 347/2019, de 8 de mayo", Revista de Jurisprudencia Laboral $(R J L), n^{\circ} 5$, 2019; e, igualmente, GARCÍA JIMÉNEZ, M.: "Derechos de sindicación y libertad sindical en las cooperativas de trabajo asociado. Comentario a la Sentencia del Tribunal Supremo (sala de lo social), de 8 de mayo de 2019. ROJ: 1944/2019", CIRIEC-España, Revista Jurídica de Economía Social y Cooperativa, n ${ }^{\circ}$ 36, 2020, pp. 423-443. DOI: https://doi.org/10.7203/CIRIEC-JUR.36.17542 
olvidar el carácter de "derecho habilitante" 115 del que goza la libertad sindical, junto a la negociación colectiva, por cuanto estos derechos constituyen instrumentos para promover y alcanzar derechos sustantivos de carácter laborales.

Entiende el Tribunal Supremo que la amplia configuración del derecho a la libertad sindical ha de conducir al reconocimiento del derecho a la libertad sindical en favor de los socios trabajadores ya que las exclusiones o limitaciones a la libertad sindical deben interpretarse siempre restrictivamente ${ }^{116}$. Tal conclusión encuentra fundamento en el artículo 28.1 CE, "todos tienen derecho a sindicarse libremente", y por otro lado, en las normas internacionales ratificadas por España, especialmente, en el Convenio 87 OIT donde se afirma que "Los trabajadores y los empleadores, sin ninguna distinción y sin autorización previa, tienen el derecho de constituir las organizaciones que estimen convenientes, así como el de afiliarse a estas organizaciones, con la sola condición de observar los estatutos de las mismas" y también en el Convenio 98 OIT en el que, igualmente, se incide en que "Los trabajadores deberán gozar de adecuada protección contra todo acto de discriminación tendente a menoscabar la libertad sindical en relación con su empleo... Dicha protección deberá ejercerse especialmente contra todo acto que tenga por objeto:(a) sujetar el empleo de un trabajador a la condición de que no se afilie a un sindicato o a la de dejar de ser miembro de un sindicato". Además, la Recomendación 193 OIT sobre promoción de las cooperativas ha de operar como criterio interpretativo y aclaratorio de los anteriores Convenios OIT que reconocen la Libertad Sindical; en ella, se hace mención a que debería alentarse a las organizaciones de trabajadores a orientar y prestar asistencia a los trabajadores de las cooperativas para que se afilien a dichas organizaciones, lo que evidencia que el principio del que se parte en los citados Convenios OIT no es otro que el reconocimiento del derecho a la libertad sindical de los trabajadores cooperativistas.

115. Vid. GIL Y GIL, J.L.: "Procedimiento por violación de la libertad sindical”. En: Procedimientos especiales de la OIT: Reflexiones y propuestas en el contexto del centenario (dir. USHAKOVA, T.), Ediciones Cinca, Madrid, 2020, pp. 164 y ss.

116. Esa ha sido la doctrina mantenida por el Tribunal Constitucional, entre otras, STC 101/1991, de 13 de mayo. En ese mismo sentido, Fundamento Jurídico quinto de la STS de 8 de mayo de 2019, antes citada: “... teniendo en cuenta lo previsto en el artículo 28.1 de la Constitución, es claro que las exclusiones y limitaciones allí establecidas o en la ley de desarrollo (LOLS) deben interpretarse de forma restrictiva, pues no es factible extender aquellas restricciones a otros supuestos de actividad o de acción sindical no comprendidos en tal precepto. Si ello se ha afirmado a propósito de exclusiones o limitaciones al ejercicio del derecho fundamental que nos ocupa establecidas en la ley, resulta totalmente lógico que la negación del derecho a la libertad sindical a colectivos no previstos explícitamente en la norma, se interprete de la misma forma; esto es, de manera absolutamente restrictiva so pena de reducir por vía interpretativa el alcance de un derecho fundamental tan amplio, subjetiva y objetivamente, como el de la libertad sindical". 
Sin duda, esta interpretación resulta coherente con el art. 10.2 CE, que exige que las normas relativas a los derechos fundamentales y a las libertades que la Constitución reconoce, se habrán de interpretar de conformidad con la Declaración Universal de Derechos Humanos y los tratados y acuerdos internacionales sobre las mismas materias ratificados por Espańa.

El Tribunal Supremo parte de "una realidad que no es posible desconocer", esto es, la presencia de un trabajo subordinado realizado por el socio trabajador que está sujeto al ámbito de organización y dirección de la cooperativa, personificada en su Consejo Rector; resulta legítimo que tales socios trabajadores puedan albergar y defender intereses estrictamente laborales, de forma alternativa a los intereses propios de la relación societaria. Por todo ello, es evidente que resultan insuficientes los habituales cauces de participación en los órganos de gobierno de las cooperativas derivados de su condición de socios. Ciertamente, la mejor evidencia de ese innegable conflicto de intereses en el marco de la prestación de servicios del socio trabajador, como ya se ha reiterado, es la atribución a la jurisdicción social la atribución de la resolución de tales conflictos (art. 2 c) LRJS y art. 87 LC), y ello, a su vez, es indicativo del nivel y ámbito de protección que el legislador quiere para este tipo de relaciones.

Esta sentencia abre posibilidades para la acción sindical de este colectivo, aunque tampoco se nos ocultan algunas dudas respecto al alcance real de tal reconocimiento y las dificultades que suscita su acción sindical, teniendo en cuenta las limitaciones del peculiar estatuto jurídico de estos socios trabajadores. Por supuesto, queda claro que el Tribunal Supremo no ha restringido dicha libertad sindical a aquellos supuestos de falsas cooperativas que encubran relaciones laborales en fraude de ley, como mantenía la Audiencia Nacional ${ }^{117}$ en el fallo que corrigió posteriormente el Tribunal Supremo; más bien, consideramos que para determinar el alcance de este reconocimiento hemos de atender a la doctrina del Tribunal Constitucional en relación al "contenido esencial" de este derecho fundamental ${ }^{118}$. De ahí que, de entrada y conforme al art. 8.1 LOLS, no veamos impedimento al reconocimiento de las facultades básicas de acción sindical, entre las que cabe resaltar la posibilidad de que se constituyan secciones sindicales en el seno de las cooperativas de trabajo asociado; entendiendo que estas podrían integrar a todos los afiliados con que cuente la correspondiente organización sindical, ya fuesen trabajadores por cuenta ajena o socios trabajadores.

117. Sentencia SOCIAL No 166/2017, Audiencia Nacional, Sala de lo Social, Sección 1, Rec 277/2017 de 17 de Noviembre de 2017.

118. "Constituyen el contenido esencial de un derecho subjetivo aquellas facultades o posibilidades de actuación necesarias para que el derecho sea recognoscible como pertinente al tipo descrito y sin las cuales deja de pertenecer a ese tipo y tiene que pasar a quedar comprendido en otro desnaturalizándose, por decirlo así." Fundamento jurídico 8º, STC 11/1981, de 8 de abril (BOE de 25 de abril). 
Ahora bien, no precisa exactamente el citado pronunciamiento del Tribunal Supremo si dicho reconocimiento de la libertad sindical en favor de los socios trabajadores, se ciñe al derecho de afiliación, excluyendo la posibilidad de fundar sindicatos específicos que representen los intereses de ese colectivo, o si, en cambio, haya de entenderse que se trata de un reconocimiento en sentido integrador de todas las manifestaciones que engloba la Libertad Sindical. A nuestro juicio, y a salvo de ulteriores aclaraciones en sucesivos pronunciamientos, si tomamos en consideración el tenor literal de la sentencia que comentamos, el Tribunal Supremo reitera hasta en dos ocasiones que "los socios trabajadores de las cooperativas de trabajo asociado tienen derecho a afiliarse al sindicato de su elección..." 119 , de lo que cabe inferir que tal reconocimiento ha de ceñirse a esa manifestación concreta de la libertad sindical, derecho de afiliación; limitación que pudiera quedar justificada por la singularidad de la posición jurídica que ocupan los socios trabajadores en el contexto de la cooperativa.

Por otro lado, en dicho pronunciamiento el Tribunal Supremo hace otra precisión relevante en lo que se refiere al derecho de actividad sindical en su vertiente colectiva, puntualizando que "los sindicatos legalmente constituidos tienen derecho al libre ejercicio de la actividad sindical en las Cooperativas de Trabajo Asociado donde tengan afiliados socios trabajadores de las mismas, tal como se desprende del texto constitucional (artículo 28.1 CE) y, específicamente, de los artículos 1.1 y 3.1 LOLS”. En este supuesto concreto, a juicio del Tribunal Supremo, los comunicados que había llevado a cabo la Cooperativa en cuestión, no se limitaron a defender una determinada postura empresarial o rebatir argumentos sindicales -lo que sería perfectamente lícito-; al contrario, contenían expresiones que, en su propio contexto, implican un acentuado nivel de desprestigio de la actividad sindical; es más, lo que se deduce de tales comunicados es una velada amenaza de que la afiliación o la contribución a la actividad sindical del sindicato en cuestión pone en peligro no sólo los puestos de trabajo en general, sino, de manera especial, los de los socios que colaboren activamente con dicha actividad. Tales comunicados del Consejo Rector remitidos a todos los socios, constituyen una vulneración de la libertad sindical, pues, están directamente dirigidos a socavar el prestigio del sindicato demandante, atribuyéndole intenciones diferentes a las de defensa de los derechos de los socios trabajadores y encaminadas a hacerles perder sus puestos de trabajo. No estamos en presencia de explicaciones sobre la actitud de la empresa en el conflicto que pudieran ser diferentes a las defendidas por el sindicato, lo que se está poniendo en cuestión, directamente, es la propia 
actividad sindical a la que se califica de opuesta a los intereses de los trabajadores a los que dice representar. Constatados los indicios que ponen de manifiesto una conducta lesiva de libertad sindical, la cooperativa no aportó una justificación objetiva y razonable que pudiese amparar su conducta y el contenido de sus comunicados, como así exige el art.181.2 LRJS. Por otro lado, reconocida la vulneración del derecho fundamental, el art. 183.3 LRJS determina que la cuantificación de la correspondiente indemnización la determinará el Tribunal prudencialmente, cuando la prueba de su importe exacto resulte demasiado difícil o costosa para resarcir suficientemente a la víctima, así como para contribuir a la finalidad de prevenir el daño ${ }^{120}$. Para ello, la jurisprudencia viene utilizando el criterio orientador de las sanciones pecuniarias previstas por la LISOS $^{121}$ para los supuestos de vulneración de la libertad sindical ${ }^{122}$, que oscilan dentro de un amplio margen en función del grado (mínimo, medio o máximo) que se aplique, atendiendo a las circunstancias que puedan considerarse agravantes ${ }^{123} \mathrm{o}$ atenuantes ${ }^{124}$ de la conducta lesiva.

Por otro lado, el pronunciamiento del Tribunal Supremo ha contribuido, igualmente, en el terreno procesal a puntualizar la posición de los sindicatos en relación con el art. 2.c) LRJS que atribuye al orden jurisdiccional social las cuestiones litigiosas que se promuevan entre las cooperativas de trabajo asociado y sus socios trabajadores, en relación a los conflictos derivados de la prestación de sus servicios. Se trata de una "remisión total", lo que quiere decir que no excluye la intervención sindical en defensa de los derechos de los trabajadores -también la de los socios trabajadoresampliamente acogida en la LRJS, y concretamente, explicitada en los art. 20 y 177.2 LRJS, que se refieren precisamente a la intervención sindical en el proceso laboral en defensa de los derechos e intereses de los trabajadores.

Por tanto, también en el plano colectivo, esta sentencia del Tribunal Supremo abre nuevos horizontes a la acción sindical, si bien, al igual que ocurre en el marco de la acción sindical individual, la actuación de los sindicatos respecto de los socios

120. Los últimos pronunciamientos del Tribunal Supremo hacen mayor hincapié en el fin preventivo frente al resarcitorio.

121. Real Decreto Legislativo 5/2000, de 4 de agosto, por el que se aprueba el texto refundido de la Ley sobre Infracciones y Sanciones en el Orden Social (BOE 8 de agosto).

122. STC 247/2006. SSTS de 8 de julio de 2014, (rcud. 282/13) y de 2 de febrero de 2015 (rcud. 279/13).

123. La prolongación en el tiempo de la conducta lesiva; el alcance de la publicidad de la lesión (por ejemplo, páginas web de acceso general); y la reincidencia.

124. En el caso que nos ocupa, respecto a la libertad sindical en el contexto de socios trabajadores, la extraordinaria complejidad jurídica del fondo de la cuestión y el marco en el que se desenvuelve, podría, no justificar la conducta, pero sí afectar a su gravedad. 
trabajadores encuentra las limitaciones que se derivan de su peculiar estatuto jurídico. Así, algunas de las manifestaciones de este derecho en el plano colectivo podrían verse condicionadas en cuanto a su ejercicio efectivo.

Podemos concluir este punto, apuntando que también en el ámbito de los derechos colectivos deberían aprovecharse los impulsos normativos de carácter supranacional. Nos referimos de un lado, al importante aporte que la OIT puede realizar en su labor de control respecto del cumplimiento y aplicación por parte de los Estados de los convenios fundamentales del trabajo a las personas socias trabajadoras de las cooperativas de trabajo asociado, particularmente, en relación al Convenio 87 OIT, "Convenio relativo a la libertad sindical y a la protección del derecho de sindicación". Y, en el plano comunitario, podemos destacar la Directiva 2003/72/CE del Consejo, de 22 de julio de 2003 por la que se completa el "Estatuto de la sociedad cooperativa europea en lo que respecta a la implicación de los trabajadores" en la que se prevén mecanismos de información y consulta a los trabajadores y, por tanto, de participación colectiva que guardan paralelismos con la dimensión colectiva de los derechos laborales que analizamos.

\section{Conclusiones}

Primera: Tomando en consideración los propósitos y misión de la ACI dentro del “Plan Estratégico 2020-30", donde se reconoce la necesidad de prestar más atención a la dignidad del trabajo como uno de los desafíos pendientes, podemos concluir que combatir la desigualdad de las condiciones de trabajo de los socios trabajadores, procurando una legítima equiparación a las condiciones laborales y derechos reconocidos para los trabajadores por cuenta ajena, constituye una plausible meta a alcanzar dentro de sus ejes de actuación para esta década. No combatirlo podría considerarse un atentado contra los principios y valores cooperativos, consagrados por la ACI y recogidos como anexo de la Recomendación 193 OIT, de donde se extrae uno de los pilares centrales de la economía social y solidaria que es un enfoque de la economía centrado en las personas.

Segunda: El carácter societario de la relación existente entre la persona socia trabajadora y la cooperativa, establecido por ley, así como el heterogéneo marco legislativo autonómico derivado a su vez del marco competencial establecido en la Constitución Española, no debe constituir una justificación para no llevar a cabo intervenciones en clave de tutela, garantizando un estatuto jurídico de carácter uniforme e igualitario para dicho colectivo de personas socias trabajadoras; y, ello, y sin necesidad de desdi- 
bujar ni alterar esa figura jurídica a la que no se le otorga la condición de trabajadores stricto sensu.

Tercera: Se han de aprovechar las sinergias derivadas de las regulaciones a nivel internacional (OIT) y de las iniciativas a nivel comunitario que potencian la economía social, para llevar a cabo un decidido impulso a la consolidación de unos estándares laborales en el marco de las cooperativas de trabajo asociado. De un lado, el concepto de trabajo decente configurado en el marco de la OIT, constituye el baluarte jurídico para abordar de forma conjunta y unitaria unos mínimos estándares de regulación, aplicables a todas las personas trabajadoras, en particular, al colectivo que nos ocupa, los socios trabajadores. De otro lado, los apoyo de la Unión Europea a este sector como eje para la reconstrucción social y económica de la UE y, particularmente, la puesta en marcha de un Estatuto jurídico para la empresa social europea, con el objeto de crear la "Etiqueta europea de economía social", han de favorecer la consolidación de "buenas prácticas laborales" en el marco de las cooperativas de trabajo asociado.

Cuarta: Los Estados desempeñan un papel fundamental en los objetivos descritos, no solo reforzando la implementación de unos adecuados estándares laborales a través de políticas públicas que de forma cualitativa valoren esos avances sociales, sino también llevando a cabo efectivos controles periódicos que verifiquen su efectividad y, consecuentemente, imponiendo sanciones adecuadas ante su incumplimiento. Políticas públicas en este sentido sentarían las bases para llevar a cabo reformas legislativas en esa línea, siguiendo algunas de las medidas ya contempladas a nivel autonómico, como por ejemplo, la igualación de los anticipos societarios a los salarios previstos en el convenio colectivo correspondiente; sería deseable que tales prácticas se extendieran al resto de condiciones laborales. Igualmente, deberían favorecerse políticas de igualdad de género, impulsos al empleo de los jóvenes o colectivos vulnerables, o también, favorecer medidas de conciliación de la vida familiar y profesional que se traduzcan de forma efectiva en una corresponsabilidad de ambos progenitores, etc. Y ello, además, claro está, de otras políticas en favor del "empleo verde" y de energías renovables, que sean respetuosas con el planeta. Todo ello, contribuiría a que las cooperativas de trabajo asociado representen efectivamente una alternativa de trabajo digno, sostenible e inclusivo, acorde con los propósitos de la ACI.

Quinta: El reconocimiento de unos estándares mínimos laborales para los socios trabajadores contribuye también a luchar contra el "falso cooperativismo". Es sabido que el recurso al cooperativismo no siempre responde a los objetivos y principios que lo inspiran, sino que algunas iniciativas empresariales lo utilizan como alternativa para eludir la legislación laboral, pues, el marco cooperativo puede ofrecerles mayor rentabilidad, reducción de costes salariales y sociales, así como, menos controles y 
exigencias al poder de dirección empresarial, e igualmente, menor o nulo control sindical. Estas prácticas, situadas en el marco de la cesión ilegal de trabajadores, no solo son contrarias a los fines de utilidad social y principios que inspiran el cooperativismo, sino que además contribuyen a generar competencia desleal, que a la postre y en última instancia, redunda negativamente en las personas que prestan servicio en tales entidades.

Sexta: El reconocimiento del derecho a la libertad sindical en el contexto de los socios trabajadores de cooperativas de trabajo asociado, abre posibilidades a la acción sindical, tanto a título individual como colectiva. A falta del reconocimiento de otros canales de representación para la promoción y defensa de los intereses de las personas socias trabajadoras en el marco de la prestación de servicios, la vía sindical despliega todos sus resortes en el ámbito de estas cooperativas, lo que sin duda se ha de traducir en motor de cambio y avance en el reconocimiento y ejercicio de los derechos laborales. 


\section{Bibliografía}

ALTZELAI ULIONDO, I.: "Un marco jurídico para la empresa social en la Unión Europea”, CIRIEC-España, Revista Jurídica de Economía Social y Cooperativa, $\mathrm{n}^{\mathrm{o}}$ 37, 2020, pp. 105-140. DOI: https://doi.org/10.7203/CIRIEC-JUR.37.17845 ARROYO SÁNCHEZ, P.: "La Constitución Española y las Cooperativas de Trabajo Asociado", CIRIEC-España, Revista Jurídica de Economía Pública, Social y Cooperativa, no 47, 2003, pp. 69-78.

CANALDA CRIADO, S.: "Las cláusulas sociales en la contratación pública: un estudio de su idoneidad para el fomento de la economía social", CIRIEC-España, Revista Jurídica de Economía Social y Cooperativa, no 35, 2019, pp. 65-94.

- "El fomento del empleo decente y sostenible en cooperativas y sociedades laborales", REVESCO. Revista de Estudios Cooperativos, no 132, 2019, pp. 77-96. DOI: https://doi.org/10.5209/REVE.65485

COMISIÓN EUROPEA [CE]: Comunicación de la Comisión al Parlamento Europeo, al Consejo, al Comité Económico y Social Europeo y al Comité de las Regiones: Iniciativa a favor del emprendimiento social. Construir un ecosistema para promover las empresas sociales en el centro de la economia y la innovación sociales, COM (2011) 682 final, Bruselas, 25 octubre, 2011.

DÍAZ RODRÍGUEZ, J.M.: "El mandato constitucional del fomento cooperativo y su desarrollo legislativo, 40 años después", CIRIEC-España, Revista Jurídica de Economia Social y Cooperativa, no 34, 2019, pp. 51-89.

ESCRIBANO GUTIÉRREZ, J.: "Cooperativas de trabajo asociado y derechos laborales colectivos de los socios-cooperativistas", Revista de Derecho Social (RDS), no 49, 2010, pp. 97-124.

— "Empleo de calidad y cooperativas de trabajo asociado: trabajadores por cuenta ajena y socios trabajadores”, CIRIEC-España, Revista Jurídica de Economía Social y Cooperativa, no 24, 2013, pp. 199-224.

ESPÍN SÁEZ, M.: El socio trabajador. Criterios para sistematizar la realidad del autoempleo colectivo, Consejo Económico y Social (CES), Madrid, 2009.

FAJARDO GARCÍA, I.G. (dir.) \& SENENT VIDAL, M.J. (coord.): Cooperativa de trabajo asociado y estatuto jurídico de sus socios trabajadores, Tirant lo Blanch, València, 2016.

FERNÁNDEZ LÓPEZ, M.F.: "Relaciones laborales especiales y Estatuto de los Trabajadores", RPS, no 189, 1983. 
GARCÍA JIMÉNEZ, M.: "La discriminación del trabajo cooperativizado", CIRIEC-España, Revista de Economía Pública, Social y Cooperativa, no 52, 2005, pp. 387-409.

— "El desamparo del trabajo asociado por la legislación laboral o el limbo del trabajo cooperativizado", Revista General de Derecho del Trabajo y de la Seguridad Social, no 37, 2014, pp. 105-122.

— "Falsas cooperativas, usos abusivos y derechos de los trabajadores. Análisis jurisprudencial y propuestas de actuación”, CIRIEC-España, Revista Jurídica de Economia Social y Cooperativa, no 33, 2018, pp. 185-222.

- "Derechos de sindicación y libertad sindical en las cooperativas de trabajo asociado. Comentario a la Sentencia del Tribunal Supremo (sala de lo social), de 8 de mayo de 2019. ROJ: 1944/2019”, CIRIEC-España, Revista Jurídica de Economía Social y Cooperativa, no 36, 2020, pp. 423-443.

DOI: https://doi.org/10.7203/CIRIEC-JUR.36.17542

GARCÍA MURCIA, J. \& ÁNGEL QUIROGA, M.: "La libertad sindical en las sociedades cooperativas de trabajo asociado. STS-SOC núm. 347/2019, de 8 de mayo", Revista de Jurisprudencia Laboral (RJL), no 5, 2019.

GIL Y GIL, J.L.: "Procedimiento por violación de la libertad sindical". En: Procedimientos especiales de la OIT: Reflexiones y propuestas en el contexto del centenario (dir. USHAKOVA, T.), Ediciones Cinca, Madrid, 2020, pp. 153-180.

LÓPEZ CANO, A.: Teoría jurídica de la economía social, Consejo Económico y Social (CES), Madrid, 2002.

LÓPEZ GANDÍA, J.: Las cooperativas de trabajo asociado y la aplicación del derecho del trabajo, Tirant lo Blanch, València, 2006.

MERCADER UGUINA, J.R.: "Contrato de trabajo y contrato de sociedad: una larga historia de encuentros y desencuentros", Nueva Revista de Derecho del Trabajo, no 172, 2015, pp. 21-60.

MONEREO PÉREZ, J.L. \& PERÁN QUESADA, S.: "Configuración y sentido político-jurídico y técnico-jurídico del trabajo decente". En: El trabajo decente (dirs. MONEREO PÉREZ, J.L., GORELLI HERNÁNDEZ, J. \& VAL TENA, A.L. de), Editorial Comares, Granada, 2018, pp. 3-18.

MONEREO PÉREZ, J.L. \& TRIGUERO MARTÍNEZ, L.A.: "La configuración técnica de la relación laboral del socio trabajador de cooperativas de trabajo asociado", Revista General de Derecho del Trabajo y de la Seguridad Social, no 37, 2014.

MONTOYA MELGAR, A: "Sobre el socio-trabajador de la cooperativa de trabajo asociado". En: Estudios de Derecho del Trabajo en memoria del profesor Gaspar Bayón Chacón, Editorial Tecnos, Madrid, 1980, pp. 139-154. 
MORGADO PANADERO, P.: "El régimen laboral y de Seguridad Social de los socios trabajadores en las cooperativas de trabajo asociado", Actualidad Laboral $(A L), \mathrm{n}^{\circ} 28,2002$, pp. 565-585.

NIEVES NIETO, N. de: Cooperativas de trabajo asociado: aspectos jurídico-laborales, Consejo Económico y Social (CES), Madrid, 2005.

NOGUEIRA GUASTAVINO, M.: "Artículo 129: la participación de los interesados en la Seguridad Social y en la empresa”. En: Comentario a la Constitución Española. 40 aniversario 1978-2018: Libro-homenaje a Luis López Guerra (dirs. PÉREZ TREMPS, P., SÁIZ ARNAIZ, A. \& coord. MONTESINOS PADILLA, C.), Vol. 2, Tirant lo Blanch, València, 2018, pp. 1799-1809.

ORTIZ LALLANA, M.C.: La prestación laboral de los socios en las cooperativas de trabajo asociado, J. M. Bosch Editor, Barcelona, 1989.

PALOMEQUE LÓPEZ, M.C.: "El trabajo autónomo y las propuestas de refundación del Derecho del Trabajo", Relaciones Laborales: Revista crítica de teoría y práctica, no 1, 2002, pp. 429-444.

PRADO REYES, F.J. \& VIDA SORIA, J.: "Artículo 129: Principios constitucionales sobre la participación social: aplicación y desarrollo". En: Comentarios a la Constitución Española. Tomo X (dir. ALZAGA VILLAAMIL, O.), EDERSA, Madrid, 1998.

RODRÍGUEZ SANTOS, E.: "El régimen retributivo de las personas socias en las sociedades cooperativas de trabajo: una revisión crítica de los modelos normativos", Temas laborales: Revista andaluza de trabajo y bienestar social, no 144, 2018, pp. 53-87.

RODRÍGUEZ-PIÑERO Y BRAVO FERRER, M.: "Prólogo". En: Procedimientos especiales de la OIT: Reflexiones y propuestas en el contexto del centenario (dir. USHAKOVA, T.), Ediciones Cinca, Madrid, 2020, pp. 9-22.

RODRÍGUEZ-PINEERO ROYO, M. \& CASAS BAAMONDE, M.E.: "El trabajo autónomo y el Derecho del Trabajo", Relaciones Laborales: Revista crítica de teoría $y$ práctica, $\mathrm{n}^{\circ} 1,2000$, pp. 73-90.

ROJO TORRECILLA, E.: "Notas a la ley de presupuestos, y a la de acompañamiento, de Cataluña para 2017. La oferta pública de empleo, y una importante modificación de la Ley catalana de cooperativas. ¿Laboralización del cooperativismo de trabajo asociado?", El Blog de Eduardo Rojo, 2 abril, 2017. Recuperado de http://www.eduardorojotorrecilla.es/2017/04/notas-la-ley-de-presupuestos-yla-de.html 
ROJO TORRECILLA, E. \& CAMAS RODA, F.: "Comentario del artículo 129.2 de la Constitución Española de 1978 y su desarrollo (con especial atención a la participación en la empresa)". En: El modelo social en la Constitución Española de 1978 (dir. SEMPERE NAVARRO, V.), Ministerio de Trabajo y Asuntos Sociales, Madrid, 2003.

SANTIAGO REDONDO, K.M.: Socio de cooperativa y relación laboral, IBIDEM Ediciones, Madrid, 1998.

SOCIAL ECONOMY EUROPE [SEE]: El futuro de las politicas europeas para la Economia Social: Hacia un Plan de Acción, Bruselas, 2018.

TOMÁS MATAIX, D.: "Prestación por desempleo y socios trabajadores de cooperativas de trabajo asociado. Sobre la posible concesión de la prestación por desempleo a personas socias trabajadoras convivientes y unidos por relación de parentesco. Comentario a la sentencia 752/2020, de 10 de septiembre, de la Sala de lo Social del Tribunal Supremo", CIRIEC-España, Revista Jurídica de Economía Social y Cooperativa, no 37, 2020, pp. 327-338.

DOI: https://doi.org/10.7203/CIRIEC-JUR.37.19142

VICENT CHULIÁ, F.: "La sociedad cooperativa europea", CIRIEC-Revista, Jurídica de Economia Social y Cooperativa, no 14, 2003, pp. 51-82. 